\title{
LA RESTAURACIÓN DE LA IGLESIA DE SANTA MARÍA DEL CASTILLO DE CASTELLDEFELS (BARCELONA, ESPAÑA)
}

\author{
(RESTORATION OF SANTA MARIA OF THE CASTLE OF CASTELLDEFELS CHURCH, \\ BARCELONA, SPAIN)
}

Antoni González Moreno - Navarro, Arquitecto

Jefe del Servicio del Patrimonio Arquitectónico Local de la Diputación de Barcelona

Fecha de recepción: 29-VIII-96

\begin{abstract}
RESLMMNN
La iglesia aneja al castillo de Castelldefels, ambos edificios de propiedad municipal, ha sido restaurada para su uso como espacio cultural y punto de información histórica de un municipio que ha sufrido un rápido crecimiento. En el presbiterio pueden verse los restos de los primeros asentamientos ibéricos y romanos $y$, en una capilla, los grafitos que dejaron los combatientes de las Brigadas Internacionales que ocuparon el castillo durante la Guerra Civil, entre 1938 y 1939. El edificio ha recuperado también su apariencia de iglesia fortificada de muros blancos.
\end{abstract}

\section{SUMMARY}

The church next to the castle of Castelldefels both municipal property) has been restored for its use as civic center and meeting point for historical studies related to that fast growing township. In its presbitery traces of the early Iberian and Roman settlements can be seen, and also, in one of the chapels, graffiti left by International Brigades occupying the castle during the Civil War between 1938 and 1939. The church has regained yet its fortress look with white walls.
En su vertiginoso crecimiento a lo largo del siglo $\mathrm{XX}$, el caserío de Castelldefels (un municipio que en una centuria ha multiplicado por más de cien su población), atrapó notables elementos arquitectónicos, antes aislados y dispersos. Ese es el caso del castillo, situado en lo alto de un cerro, en cuya vertiente sudoeste se extiende el celebrado parque diseñado hace pocos años por los arquitectos José Antonio Martínez Lapeña y Elías Torres Tur, por el que discurren las rampas peatonales contenidas por las conocidas planchas férreas zigzagueantes.

En 1988, con la intención de convertirlos en equipamientos urbanos, el ayuntamiento compró el castillo y la iglesia a los descendientes de Manuel Girona Agrafel, el poderoso banquero y político catalán que costeó la finalización de la catedral de Barcelona a finales del siglo XIX. Ese mismo añoel consistorioinició la restauración del castillo mediante una Escuela-taller creada al efecto. Pronto, sin embargo, solicitó la ayuda de la Diputación de Barcelona para restaurar la iglesia y para la tutela científica de la intervención prevista en el castillo, destinado a albergar una escuela municipal de hostelería. Los trabajos programados y dirigidos por el servicio especializado de la Diputación se iniciaron en 1989 con los habituales estudios históricos y constructivos contemplados en el Método SCCM de restauración monumental que el SPAL utiliza. ${ }^{1}$

\section{EL MONUMENTO, DOCUMENTO HISTÓRICO}

La investigación en su conjunto dio unos resultados de gran interés, no sólo para su aplicación en la restauración de la iglesia, sino también para el mejor conocimiento del lugar y el municipio. En todo el área investigada arqueológicamente (la práctica totalidad de la superficie 


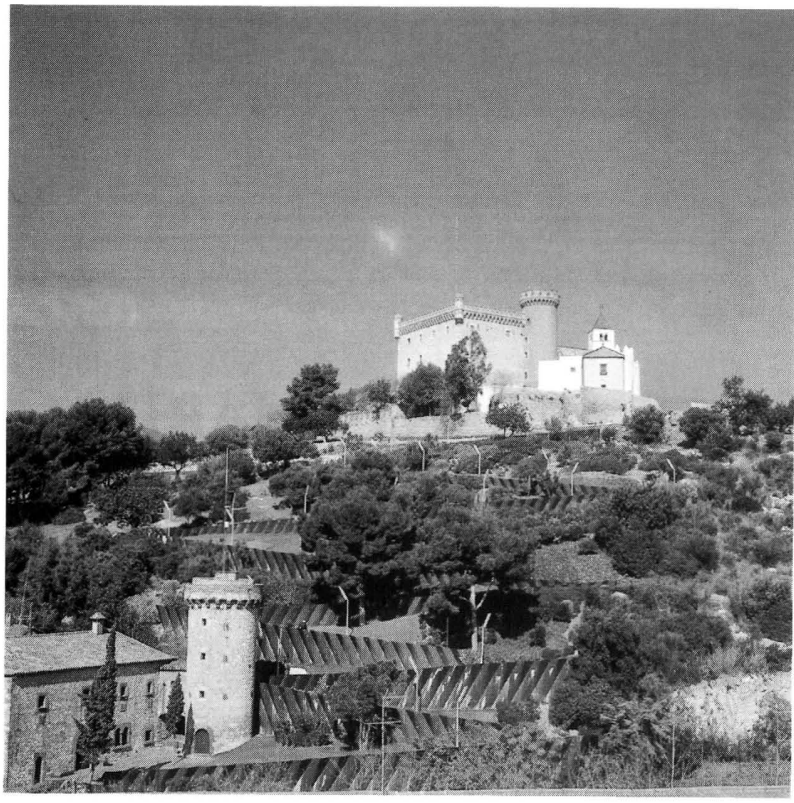

Vista del castillo y de la iglesia después de la restauración de ésta. En primertérmino, el nuevo parque del cerro. (Foto: Montserrat Baldomà, 12 demarzo de 1996.)

ocupada por el templo y algunos espacios del castillo y su entorno) aparecieron restos de un poblado ibérico activo del siglo IV al I a.C. y, superpuestos, los de una villa romana del segundo cuarto del siglo III. De éstos merece mención especial un cippus con inscripción latina datable en la primera mitad del siglo II $\mathrm{dC}$. Se trata de un monumento conmemorativo de carácter privado, con toda probabilidad el pedestal de una estatua que se hallaba en la villa romana y recordaba a uno de sus propietarios. Está dedicado a Cayo Trócina Synecdémo, liberto de Cayo, sacerdote del culto de Augusto divinizado, por su esposa Valeria Haliné, "por haber sido un esposo excelente".

En cuanto al castillo, según la investigación realizada tiene su origen en el siglo $\mathrm{X}$, aunque los restos más antiguos hallados son del XIV. De esta época data la torre circular desmochada correspondiente al recinto fortificado situada en el cementerio, frente a la fachada sur del templo. La construcción del cuerpo de levante se fijó a mediados del siglo XVI y en 1734, el de poniente. La gran torre del sudoeste fue construida en 1590, aunque su actual coronamiento (como, en general, el de todos los cuerpos del castillo) se realizó a finales del siglo XIX.

\section{La iglesia de Santa María}

El templo anejo al castillo data también, según demostró la arqueología, del siglo X. El queahora vemos es románico, levantado casi con toda certeza en el siglo XI y consagrado a principios del XII (posiblemente en 1106). Tiene nave única y transepto con tres ábsides y crucero coronado por un pequeño campanario de torre sobre el cimborrio. En el siglo XIV un sector de su perímetro fue fortificado, siendo el ábside sur y una parte del central recrecidos y coronados con almenas.

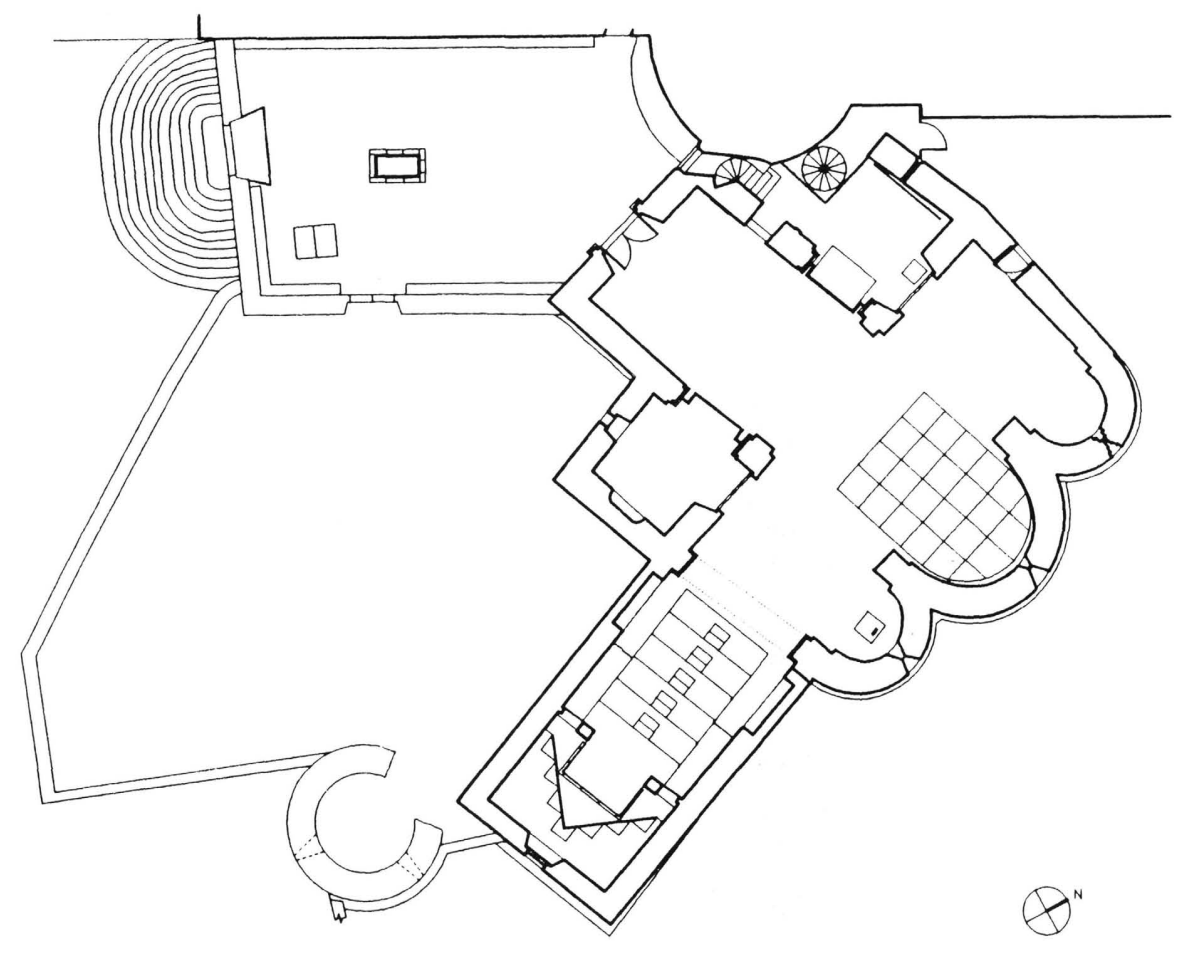


En el siglo XVI se construyeron sendas capillas a poniente de los brazos del transepto de la iglesia y debió cerrarse una posible puerta románica orientada a mediodía. De aquellas fechas data el coro situado a los pies de la nave, cuyas ménsulas y clave de la bóveda de crucería están esculpidas, respectivamente, con las figuras de los evangelistas y de la Virgen. A finales del mismo siglo XVI se construyó una portada renacentista en la fachada de poniente. Su autor fue probablemente Lleonard Bosc, artífice de las portadas -muy similares- de las cercanas iglesias de Begues, Cervelló y Sant Just Desvern. Anteesta fachada, y junto al antiguo cementerio parroquial (originario del siglo $X$, pero cuya delimitación actual data del XVIII), se dispuso entonces un patio decorado con azulejos. Para salvar el desnivel entre el nuevo patio y el terreno se construyó una sencilla escalera de piedra deplanta rectangular y un solo tramo, descubierta durante la excavación arqueológica de 1995, oculta bajo otra (de planta en forma de C), construida hacia 1734, que es la que funciona actualmente

Entre 1720 y 1724 , se adosó un cuerpo rectangular al brazo de mediodía de la iglesia, completándose la planta actual. Se trata de la capilla de la Virgen de la Salud que en su sector de mediodía cobijó el camarín de la patrona de la villa de Castelldefels. Las pinturas barrocas originales fueron recubiertas por otras neoclásicas inspiradas en el III y IV estilo pompeyano, realizadas en 1812 por el pintor Francisco Rodríguez y sufragadas "con sus propios dineros" -según mandó dejar constancia en la cornisa- por el párroco Celestí Vert.

Así debía estar el templo cuando Manuel Girona Agrafel adquirió el 12 de febrero de 1897 la baronía deEramprunyà, a la que pertenecían los terrenos de la fortaleza de Castelldefels. En pocos meses -una lápida conmemorativa cita el 31 de julio del mismo año como fecha final de los trabajos-, y bajo la dirección del reputado arquitecto catalán Enrique Sagnier y Vilavecchia, el castillo fue restaurado. Poco tiempo disfrutó el señor Girona su nueva posesión, ya que falleció en 1903. A los pocos años, a finales de la primera década del nuevo siglo, su hijo, Manuel Girona Vidal, mandaría restaurar la iglesia para uso particular de la familia (no se conoce con certeza quien dirigió las obras) y mandó construir a sus expensas una nueva parroquia en el nuevo centro del municipio (ésta sí consta que fue proyectada por el propio Sagnier), a la que en 1911 fue trasladada la imagen de la patrona, hasta entonces instalada en la capilla de la Salud de la iglesia del castillo.

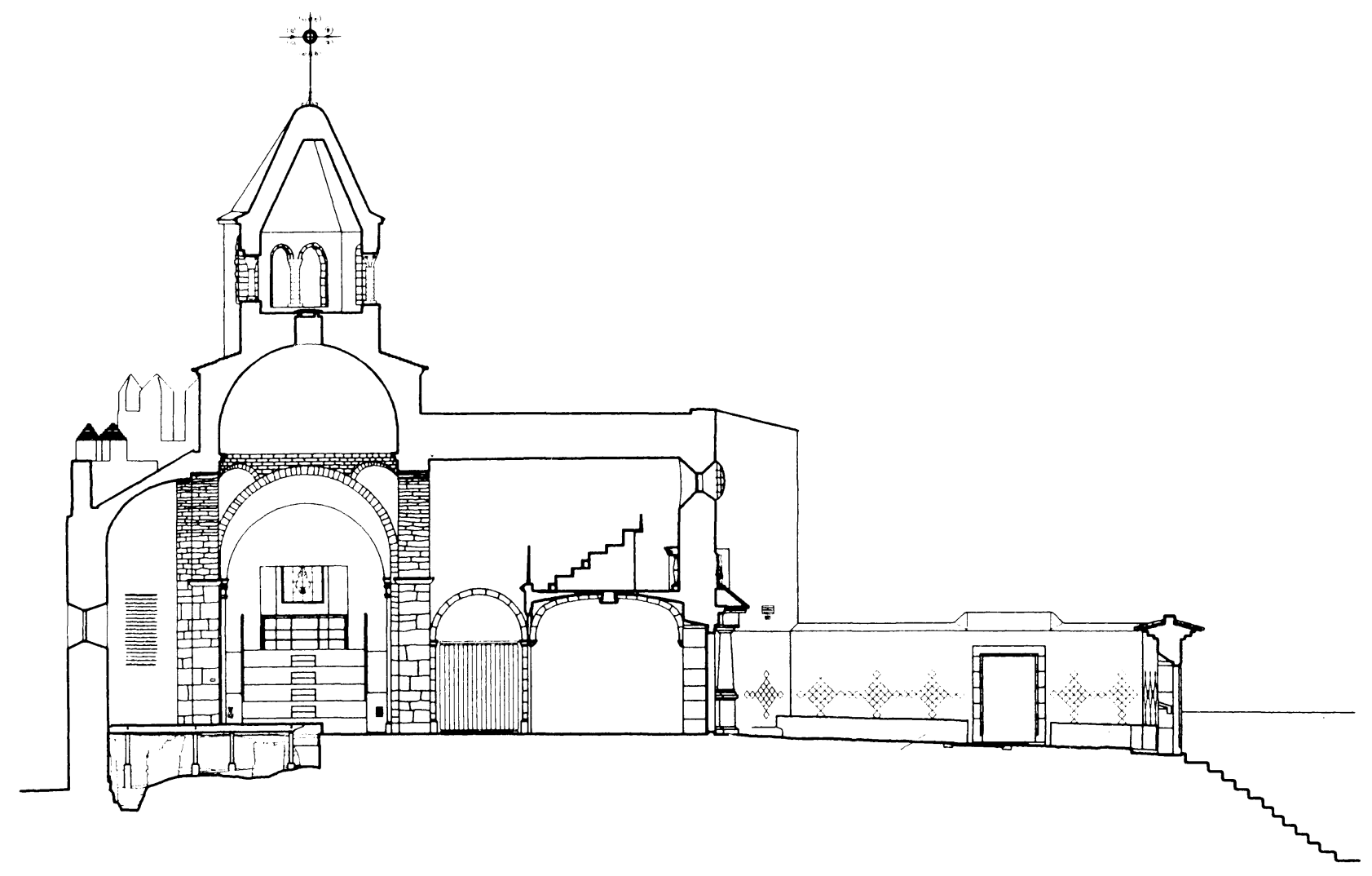




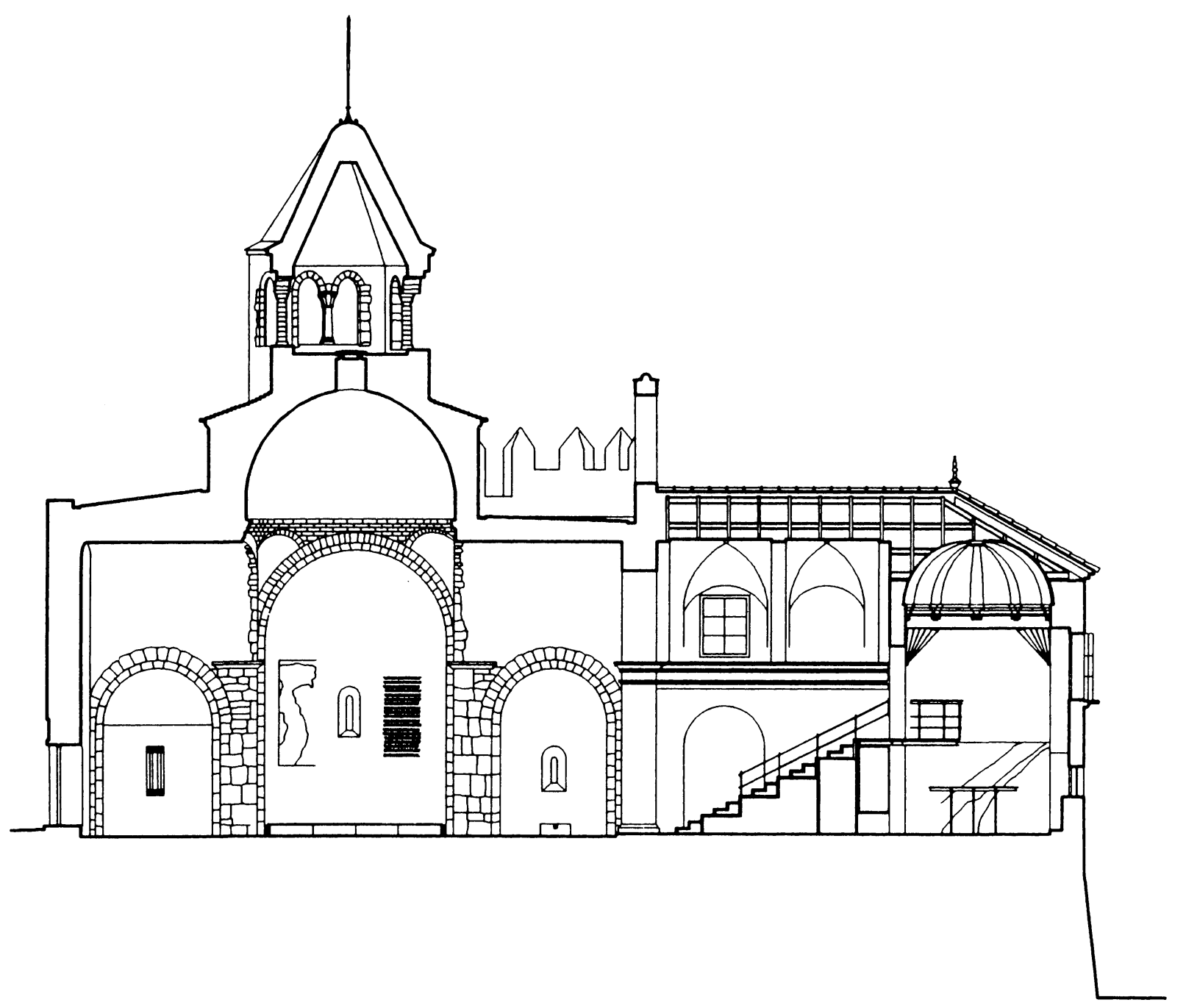

Sección transversal por el eje del transepto y la capilla de la Virgen de la Salud, después de la restauración.

\section{El crimen de Castelldefels}

Cuando la familia Girona adquirió la fortificación de Castelldefels, los lugareños aún mantenían fresca la memoria de un suceso que había conmocionado al municipio, incluso a todo el país. Había tenido lugar en 1893 en la propia casa rectoral de la iglesia del castillo, entonces aún sede de la parroquia.

La mañana del 26 de agosto de aquel año, un panadero oriundo de Aragón, Joaquín Figueras, entró furtivamente en la casa y asestó catorce puñaladas a mosén Jacint Orta Berenguer, de 60 años, natural de Vic, regente de la parroquia. También propinó 27 puñaladas y un par de disparos de arma de fuego a la sobrina del cura, Rita Bosch Orta, una hermosa muchacha de 21 años, con quien el homicida, hacía algún tiempo, había mantenido relaciones y que, según se dijo, fue forzada por su asesino sobre el lecho de muerte.

El homicida fue detenido en Barcelona el día 3 de septiembre y acabó por confesar su crimen. Calló, no obstante, los motivos, y negó siempre la imputación de haber robado y violado a la muchacha. El 25 de junio de 1894 se inició en la Audiencia Provincial de Barcelona el juicio. A los dos días el jurado dictó la culpabilidad y el tribunal la sentencia de muerte. Un año después, el 19 de junio de 1895 , unas ocho mil personas se congregaron alrededor de la explanada que se abre ante la muralla de mediodía del castillo de Castelldefels. Y allí mismo, a escasos metros del lugar del crimen, a las nueve en punto, el verdugo suministró el garrote vil al condenado. Antes, 
Joaquín Figueras -que contaba entonces 25 años de edadse dirigió al público pidiendo perdón y paz para su alma. Sus despojos fueron expuestos hasta pasadas las cinco de la tarde y enterrados después junto a los de sus víctimas.

\section{El paso de las Brigadas Internacionales}

A pesar de su dramatismo, no iba a ser ese el peor episodio criminal que conociera la iglesia de Santa María del castillo de Castelldefels. Uno aún más trágico ocurrió durantela última Guerra Civil española, cuando el castillo, desde abril de 1938 a enero de 1939, fue usado por las Brigadas Internacionales (unidades de combate formadas por voluntarios extranjeros que acudieron en ayuda de la República), obligadas a trasladar su base general desde Albacete a Barcelona a causa de la ofensiva iniciada por el general Franco a principios de 1938, con la intención de dividir en dos la zona republicana.

Los brigadistas arrestados por indisciplina fueron trasladados también y, en abril de 1938, conducidos al castillo de Castelldefels, que había sido habilitado al efecto bajo la dirección del croata Côpic. A partir de ese momento y hasta enero de 1939, según las crónicas, el castillo fue testigo de torturas y asesinatos, consecuencia trágica de los enfrentamientos ideológicos que se daban en el bando republicano. Según esas crónicas, nada más llegar, Côpic, para disminuir su número, mandó fusilar a 60 de los 265 detenidos.

Durante todo ese tiempo, el cuerpo de guardia de la prisión se instaló en la antigua capilla de la Virgen de la Salud. En sus paredes algunos de los brigadistas realizaron dibujos a lápiz -que han perdurado hasta nuestros días- que representan paisajes y personajes históricos del momento, barcos y aviones que debían de verse desde el castillo y otras representaciones, más simbólicas y fantasiosas, que dan fe de aquellos sucesos

\section{EL MONUMENTO, OBJETO ARQUITECTÓNICO}

La intervención arquitectónica iniciada en 1990 persiguió tres objetivos: revalorizar los aspectos arquitectónicos y artísticos del edificio y adaptarlo funcionalmente para un nuevo uso (actividades culturales, conciertos, celebración de matrimonios civiles, etc.), y potenciar su capacidad informativa sobre una tan agitada e interesante historia, para reforzar su carácter significativo y emblemático.

\section{Actuación en el interior}

Un aspecto decisivo de la revalorización arquitectónica del templo fue devolverle su espacio original románico, sin negar su evolución posterior. Una de las medidas fue cerrar las capillas del siglo XVI, de forma que la nave y el transepto dibujaran con claridad la primitiva planta de cruz latina. Con el mismo fin de recuperación espacial, el ábside del evangelio -que se había perdido totalmente- se reconstruyó sobre sus cimientos hallados en la excavación, y se rehizo la parte alta del ábside central, muy alterado en el siglo XVI cuando se colocó un retablo (perdido presumiblemente durante la guerra civil o trasladado a otro lugar por la familia Girona).

Encuanto a la capilla de la Virgen dela Salud, a pesar de que su volumen distorsiona la morfología románica del templo y de que su espacio (unido sin cortapisas -casi con violenciaa uno de los brazos del transepto) altera rotundamente el original, nunca se pensó en suprimirla. Se creyó que poseía suficientes alicientes y valores (decorativos y testimoniales), no sólo para ser conservada, sino incluso para ser revalorizada como parte esencial del conjunto. No obstante, para disminuir en lo posible su impacto espacial se decidieron dos intervenciones que, además, permitieran alcanzar otros objetivos.

Por una parte, se recuperó el antigúo camarín de la Virgen; con la consiguiente disminución de la profundidad de la capilla (recuperación en sí misma positiva, ya que devolvía al monumento parte de su autenticidad perdida, y que además permitía proteger mejor los grafitos allí conservados) y, de otra parte, se colocó junto al muro del camarín recuperado unas gradas que, aunquepoco, reducían (al "llenarlo") el espacio de la capilla y, además, permitian mejorar su uso -la visibilidad hacia el presbiterio- y el acceso libre al balcón que vuela sobre el espacio del antiguo camarín.

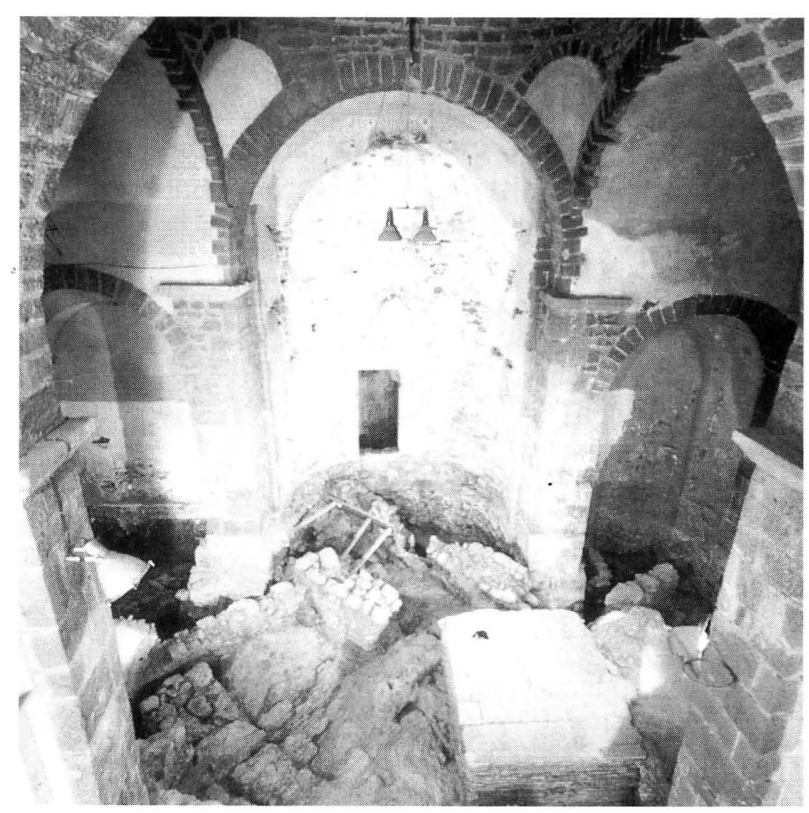

Interior del crucero y la cabecera una vez acabada la excavación en extensión del interior de la iglesia. (Foto: Josep Miquel Solé, noviembre de 1990.) 


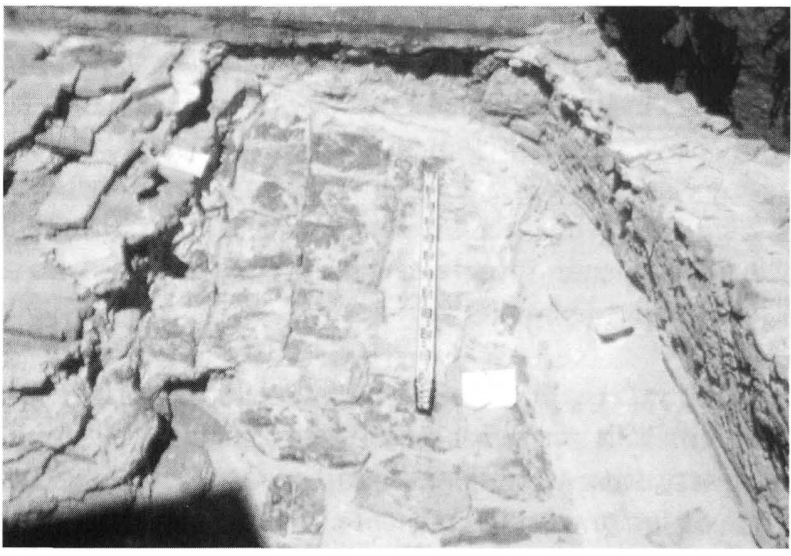

Excavación arqueológica de las cubiertas. (Foto: Montserrat Baldomà 12 de julio de 1991. )

Las gradas y la plataforma del balcón son de madera de Jatoba, de origen brasileño, dura, resistente y de buen acabado. Las planchas tienen un grueso de $45 \mathrm{~mm}$ y las verticales actúan como elementos sustentantes. El conjunto escalonado se apoya sobre muros de ladrillo y la plataforma se sustenta sobre un entramado metálico en voladizo. La baranda del balcón es metálica. El pasamano consta de una pieza de sección en $U$, en cuyo interior su sitúa un vidrio tipo laminar con dibujos y textos referentes a los grafitos. Bajo el pasamano, otro perfil en $U$ contiene los aparatos de iluminación lineal. Las barandas de las gradas son también metálicas. A ambos lados delas gradas, para controlar el paso hacia la cámara de los grafitos, se dispusieron dos puertas de vidrio de seguridad, en las que se grabaron los escudos de la Diputación barcelonesa y el ayuntamiento local.

Otro aspecto de la revalorización arquitectónica del interior (relacionado también con los objetivos informativos y funcionales) fue el tratamiento de las superficies. El pavimento del espacio original románico es de mármol rojo de Alicante, recortado en el mármol blanco de los

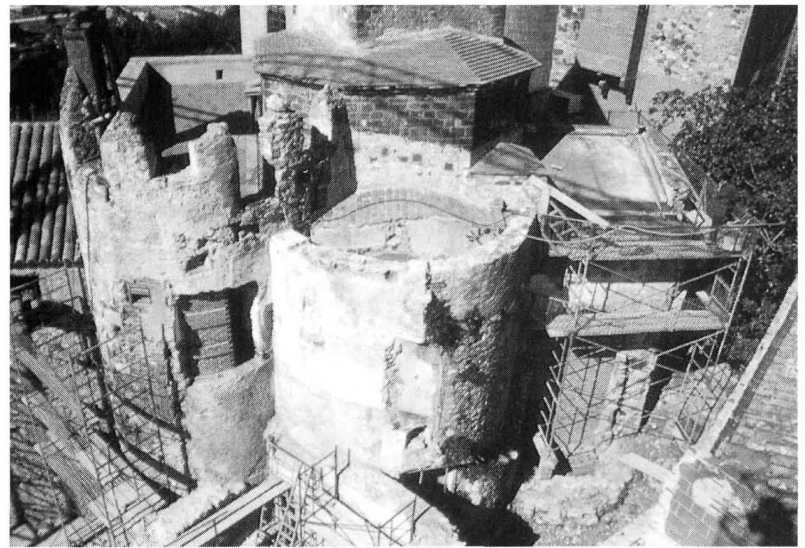

Estado en que apareció la cabecera, una vez desmontados los edificios parásitos. (Foto: Montserrat Baldomà, 26 de abril de 1994.)

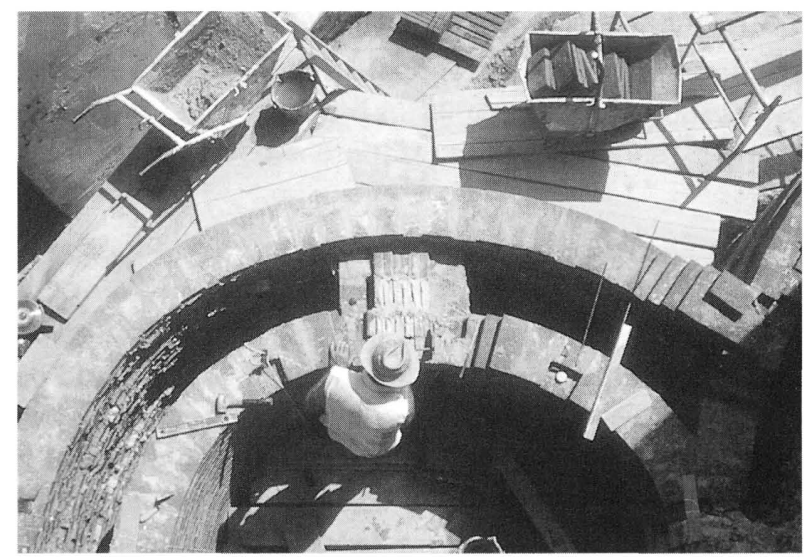

Construcción del nuevo ábside norte. (Foto: Montserrat Baldomà, julio de 1994.)

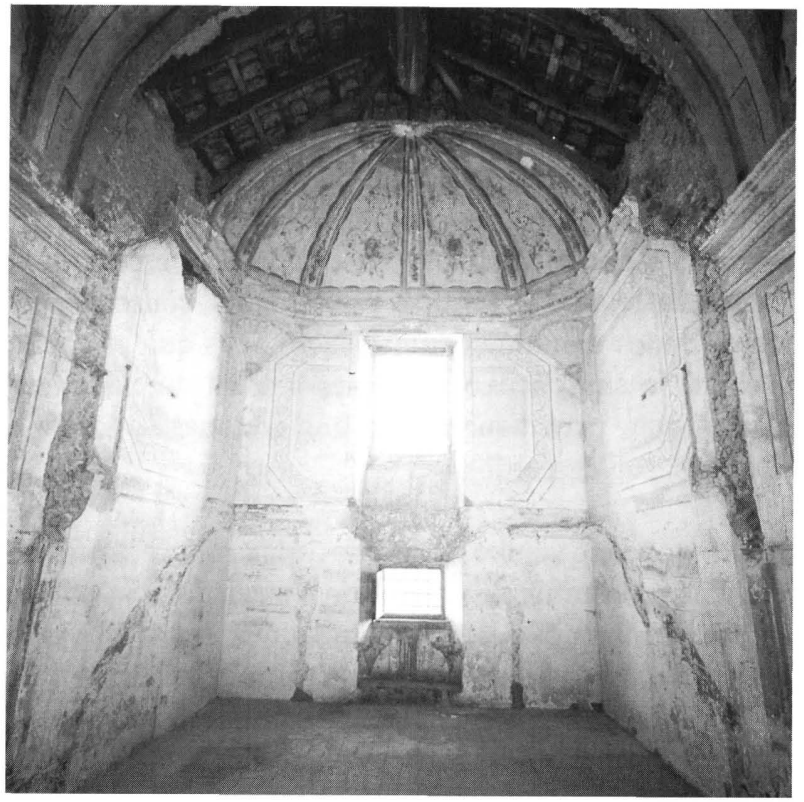

La capilla de la Virgen de la Salud, tal como se encontraba antes de iniciar los trabajos. (Foto: Josep Miquel Solé, noviembre de 1990.)

demás espacios, lo que facilita la comprensión de la evolución del edificio. En cuanto a los muros y bóvedas se optó por respetar el criterio adoptado en la restauración de 1911: dejar vista la piedra de los pilares y los arcos, y revestidos los demás paramentos y bóvedas, que ahora están pintados de color verde claro para mejorar el contraste. En cuanto a la capilla de la Virgen de la Salud, se recuperó la decoración original, siempre que ello no resultara incompatible con la conservación de los grafitos.

Como consecuencia directa del nuevo uso, cabe citar también, a parte de cuanto se refiere a las instalaciones de iluminación y acústica con que se ha dotado al edificio, la transformación del coro situado a los pies de la nave, en el que se ha situado una grada, también de madera de Jatoba, 
con capacidad para una veintena de espectadores. Para permitir una buena visibilidad se sustituyó la baranda de barrotes de escayola que allí había, por otra de vidrio. La

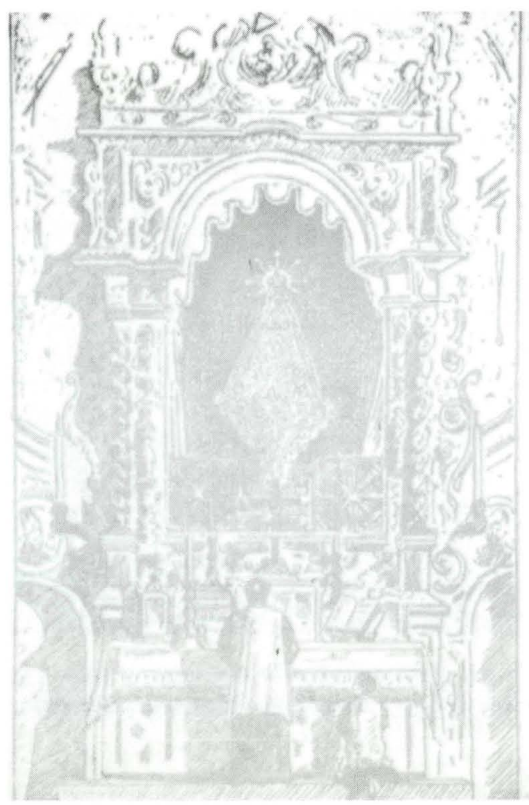

Dibujo que representa el antiguo retablo y camarin de la capilla de la Virgen de la Salud. antigua, no obstante, no se ha perdido; simplemente se ha desplazado al fondo del coro y podrá recuperar su situación primitiva cuando en el futuro así parezca oportuno.

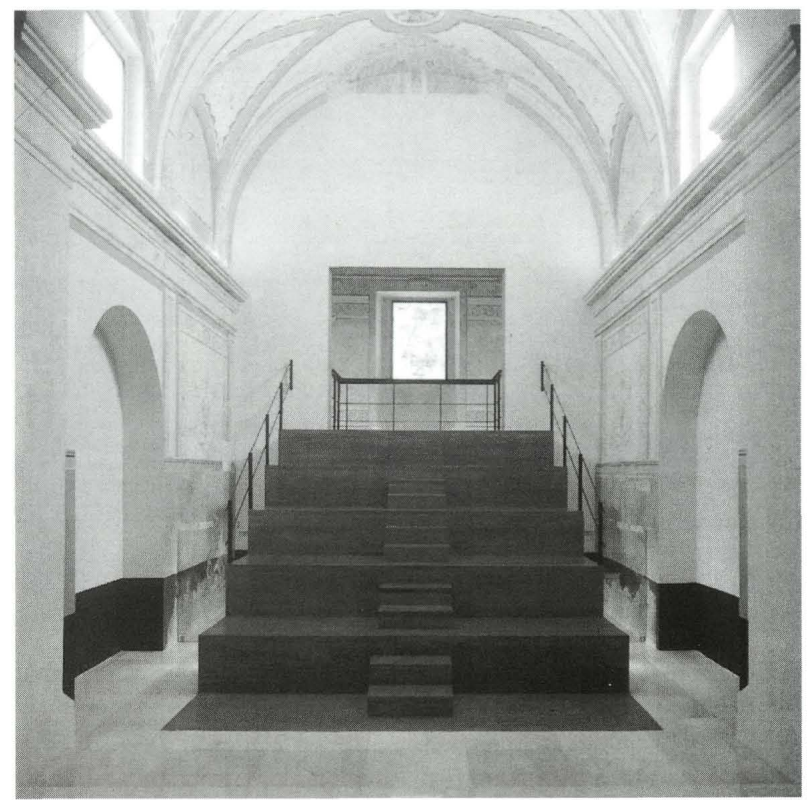

Interior de la capilla de la Virgen de la Salud, después de la restauración, con las gradas de madera de Jatoba. Al fondo, la silueta de la Virgen. (Foto: Montserrat Baldomà, 16 de marzo de 1996.)

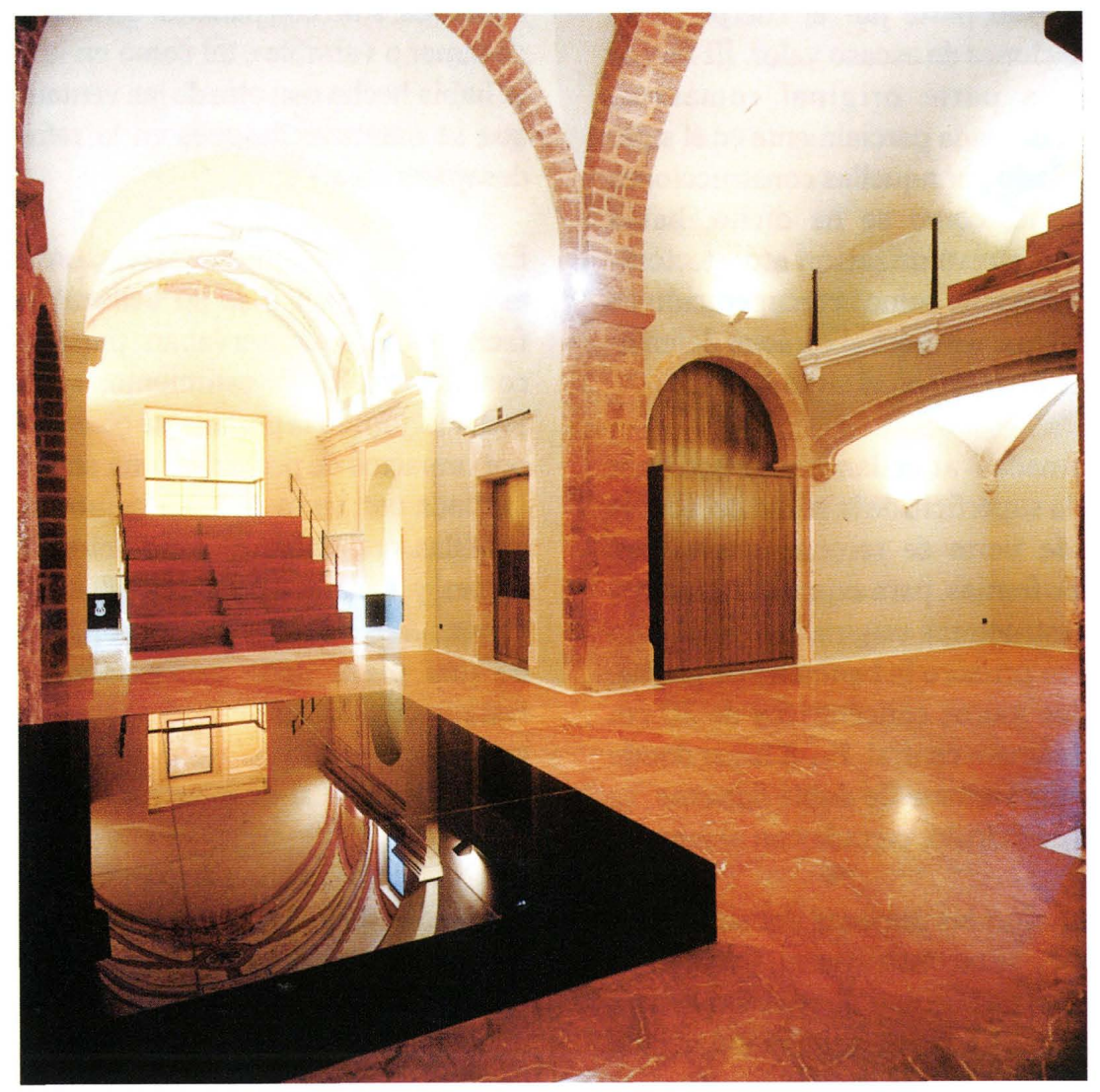

Interior del crucero y la capilla de la Virgen de la Salud, después de la restauración. (Foto: Montserrat Baldomà, 16 de marzo de 1996.) 


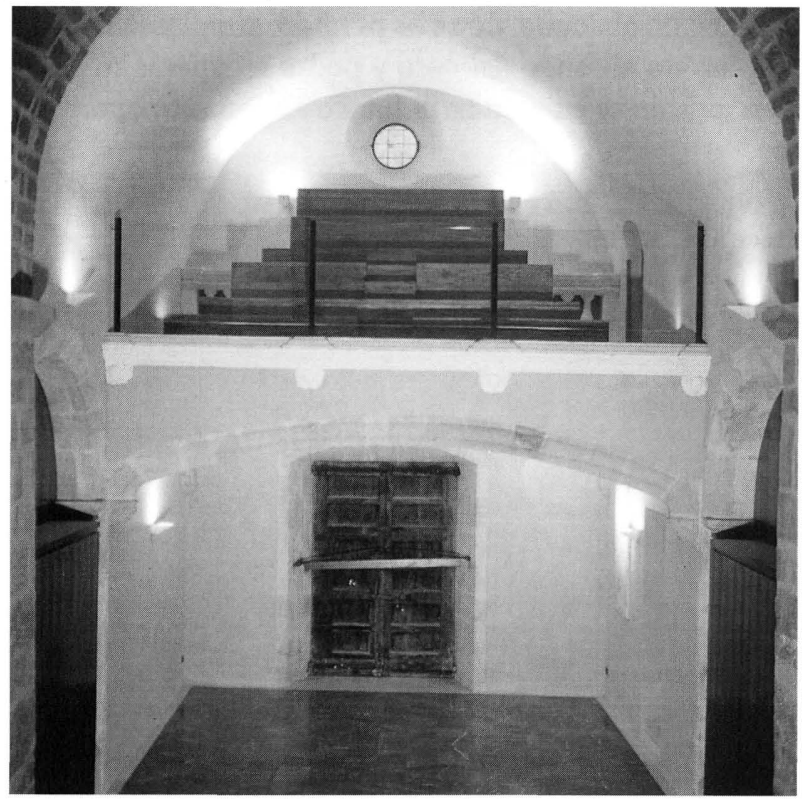

Vista de la nave y el coro, desde el presbiterio. (Foto: Montserrat Baldomà, 16 de marzo de 1996.)

\section{Actuación en el exterior}

Enel exterior, el ábsiderománico de mediodía-sobrealzado y fortificado en el siglo XIV- se encontraba antes de la restauración tapado en gran parte por el cuerpo de la sacristía y otras construcciones de escaso valor. El ábside central conservaba una parte original románica, sobreelevada también y coronada parcialmente en el siglo XIV, pero había sido dañado por aquellas construcciones anejas. Y el ábside norte, como se ha dicho, había desaparecido totalmente. La revalorización arquitectónica se entendió, en consecuencia, como la recuperación de la cabecera triabsidal, sin que perdiera el carácter defensivo que aquellas fábricas tuvieron en el siglo XIV.

Para ello fueron eliminadas aquellas construcciones parásitas, mientras que la superficiè de la mitad del ábside central y todo el ábside norte se reconstruyeron con ladrillo manual, formando franjas, para expresar claramente su diacronía con las estructuras originales. En el caso del ábside norte se realizó primero la banqueta de piedra, sobre la que se alzan dos muros concéntricos de $30 \mathrm{~cm}$ cada uno que dejan una cámara central. En el lugar donde ese ábside debió tener una ventaná de doble derrame, se situó la nueva, también de ladrillo, cerrada con alabastro.

Se conservaron y restauraron las almenas del siglo XIV que coronan el ábside sur y se reconstruyeron, también en ladrillo, dos almenas del ábside central de cuya existencia pretérita había constancia. (La parte restante del ábside central nunca tuvo almenas, ya que, como demostró la arqueología, el lienzo fortificado continuaba hacia levante, perpendicularmente al ábside.) Los muros y ventanas

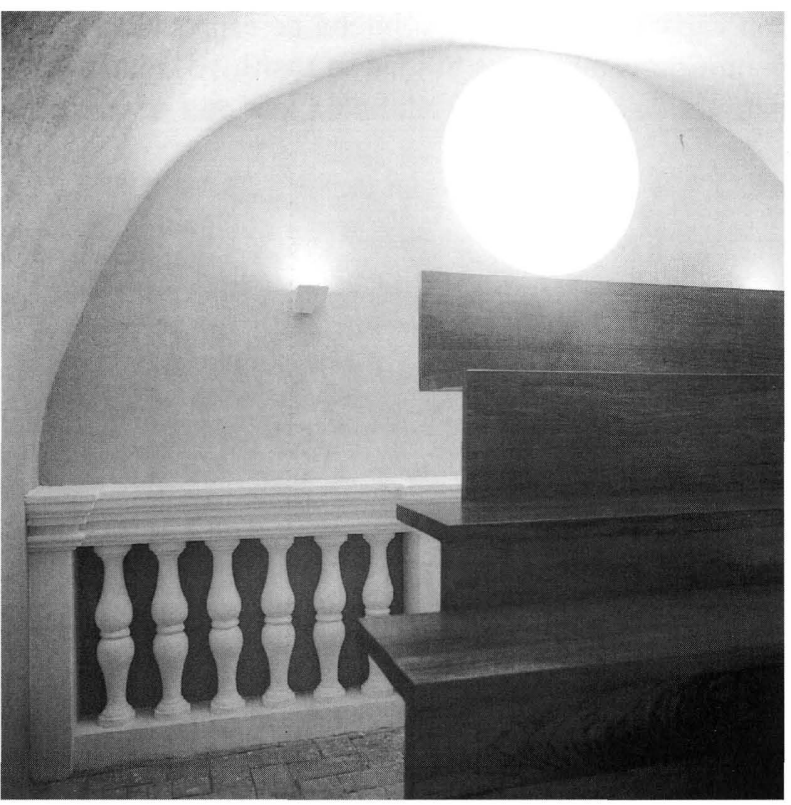

La balaustrada del coro, substituida por una de vidrio, conservada y desplazada detrás de las gradas. (Foto: Montserrat Baldomà, 16 de marzo de 1996.)

geminadas del campanario también fueron restauradas. Dos de los pilares de las ventanas y sus capiteles, que se habían sustituido por machones para mejor sustentar alguna campana nueva, fueron recuperados. No se hizo de forma mimética, sino con material cerámico (piezas octogonales de tamaño variable), tal como en la restauración de 1910 se había hecho con otra de las ventanas. (Este criterio es el que se mantuvo después en la refacción de los ábsides desaparecidos.)

En lafachada deponiente se restauró la portada renacentista (que recuperó toda su belleza) y, como en todas las fachadas que conservaban parte de los enlucidos, se completaron los revestimientos superficiales. En aquella fachada, junto a la portada, se conservaba -muy deteriorada por impactos de pedradas- una sencilla placa de cerámica vidriada con texto de color negro sobre fondo blanco, de aquéllas que daban noticia del edificio sobre el que se hallan y del municipio. Gracias a fotografias antiguas conocíamos el texto y la grafia original. Se trataba sin duda de una pieza nada excepcional, pero se decidió su restauración ya que la desaparición de estos elementos, aparentemente poco importantes, empobrecen el valor documental de nuestros monumentos.

Para evitar la negativa dispersión formal producida por la diversidad de fábricas resultantes de estas intervenciones (la piedra sin sus revestimientos originales, la piedra recubierta por antiguos enlucidos conservados o por otros nuevos, y la nueva fábrica de ladrillo), se unificó el color de todas ellas. Para ello fueron revestidas todas con un material de color blanco ligeramente teñido que, sin embargo, no impide apreciar la diversa textura de cada 


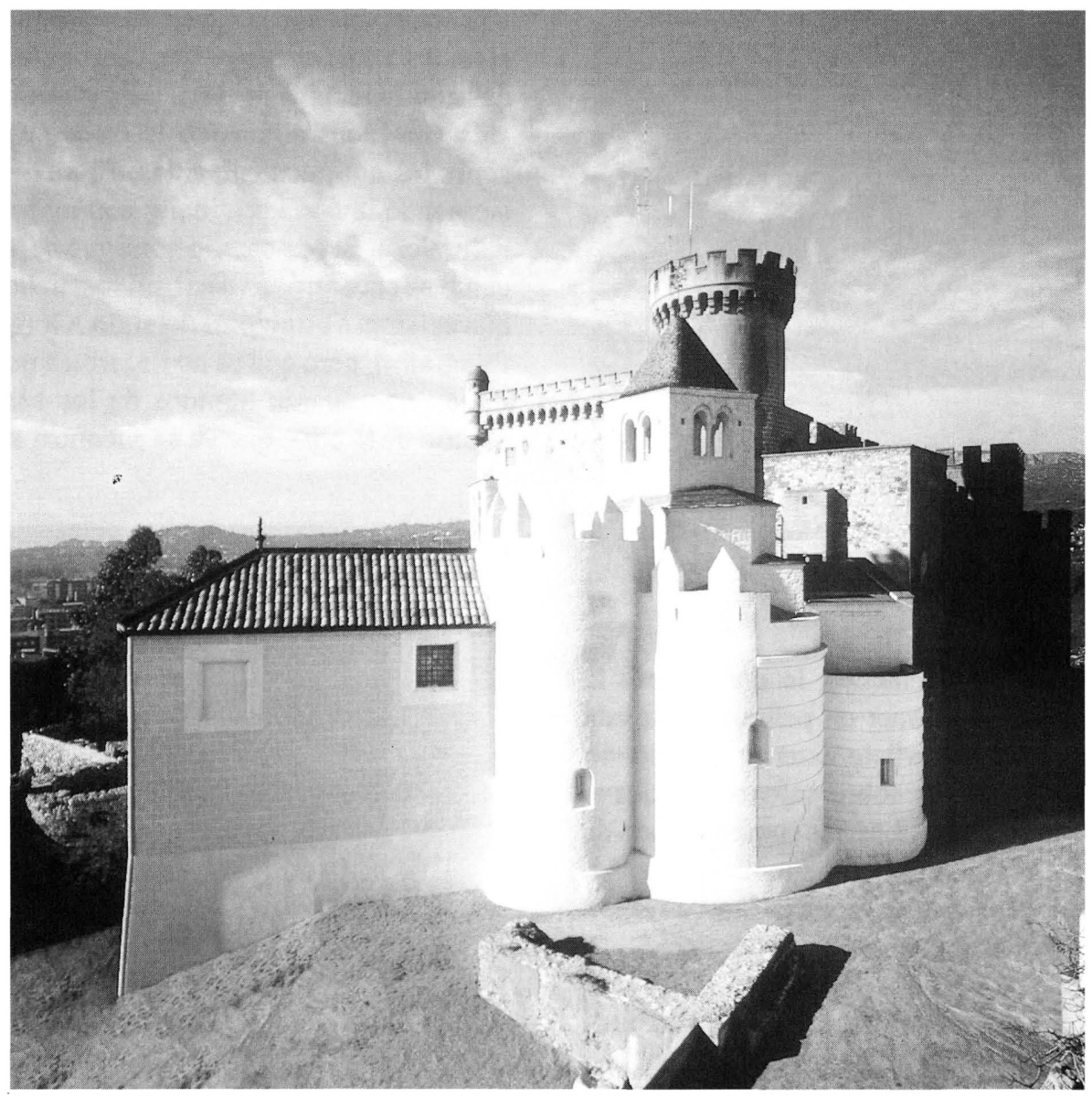

Vista de la iglesia restaurada, desde levante. (Foto: Montserrat Baldomà, 26 de enero de 1996.)

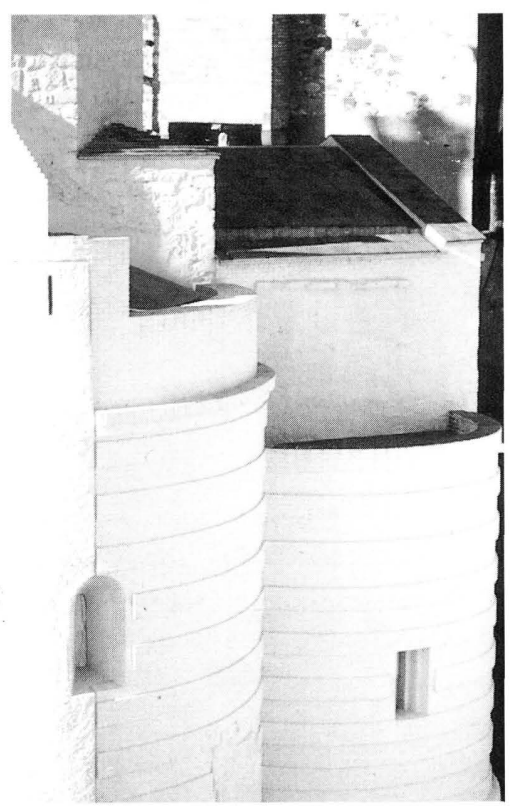

Coronación de los ábsides central y norte, una vez reconstruidos. (Foto Montserrat Baldomà, 26 de enero de 1996.) fábrica. Se trata de una mezcla de silicato con cal, arena de mármol y fibras de celulosa, aplicada en algunos casos con llana y en otros -diluida en silicato de potasa- con brocha de blanquear. En el caso dela capilla dela Salud seoptó por recuperar el original fingido de sillares sobre estuco de color azul.

La parte superior de los cuerpos de la iglesia de origen medieval (nave, transepto y cabecera) fue investigada arqueológicamente, lo que permitió conocer las sucesivas cubiertas que el templo tuvo (de piedra, teja o baldosa cerámica, según la época). La excavación, sin embargo, no se planteó en extensión, sino mediante catas para preservar el máximo de restos con vista a posibles futuras investigaciones. Una vez acabada la exploración, las catas fueron rellenadas con gravas, se impermeabilizó el conjunto con tela asfáltica armada con polietileno y se selló con piezas cerámicas. Las cubiertas desaguan mediante gárgolas cerámicas.

En cuanto a la cubierta de la capilla de la Virgen dela Salud fue necesario en primer lugar rehacer la estructura, que se encontraba en pésimo estado. Se desmontó y fue sustituida 


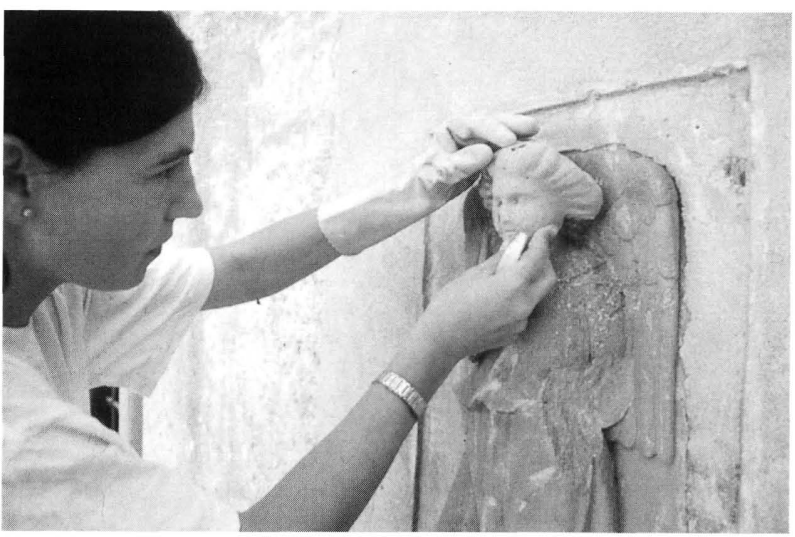

Restauración de la portada renacentista. (Foto: Montserrat Baldomà, 22 de junio de 1995.)

por otra a base de perfiles metálicos, lo que facilitó la ejecución y colocación sin poner en peligro la bóveda fingida que cobijaba. La superficie exterior se resolvió con tejas árabes tradicionales sobre solera cerámica y chapa de hormigón con mallazo. Las tres cumbreras son de teja vidriada de color verde, siguiendo el modelo original. También se reprodujo el pináculo primitivo que corona su intersección. Los canalones y bajantes son de cobre.

La bóveda fingida, hecha de doble capa de rasilla cerámica y revestida interiormente con yeso, era de cañón con lunetos en la nave de la capilla y cupular de planta rectangular achaflanada en el espacio del antiguo camarín, habiéndose perdido la mitad al desmontar el muro que delimitaba el camarín en el que se apoyaba. Esta mitad fue rehecha (los nervios se construyeron de poliuretano y los entrepaños y las pechinas con fibra de vidrio y poliéster) y el resto de la bóveda fue saneado.

La cubierta del campanario fue consolidada y el tipo de material superficial ("trencadís" cerámico, sin duda aportado en la restauración de principios de siglo) fue conservado, sustituyendo buena parte de las piezas deterioradas. En la cubierta del cuerpo octogonal del cimborrio se reprodujo con piezas cerámicas el sistema original de cubierta a base de lajas de piedra, habiendo dejado algunas piezas in situ como testimonio. De la misma manera se hizo con los extradoses de las pechinas.

\section{Actuación en el entorno}

Como es habitual en todas las restauraciones acometidas por el SPAL, se prestó una atención especial al entorno del monumento, aunque en este caso la actuación no ha podido aún ser completada y, de momento, sólo ha afectado a los espacios inmediatos de poniente (patio, cementerio y acceso).

En el patio que se abre ante la portada renacentista de finales del siglo XVI, se han recuperado los azulejos de

(c) Consejo Superior de Investigaciones Científicas Licencia Creative Commons 3.0 España (by-nc) aquella misma época mediante reproducciones, siguiendo el modelo de algunas piezas que se conservaban, realizadas con la técnica original de sucesivas plantillas, y han sido colocados siguiendo la traza que aún se dibujaba sobre los antiguos enlucidos. El pavimento fue rehecho siguiendo la traza original y con materiales de la misma naturaleza. El cementerio contiguo se ha conservado tal y como se encontró, es decir sin los nichos ni la capilla que aún existían a principios del siglo XX (que conocemos por fotografia), pero que ya no llegaron a nuestros días. En un rincón se situaron algunos de los bloques del antiguo padrón de la cruz, que ya se encontró desmontado.

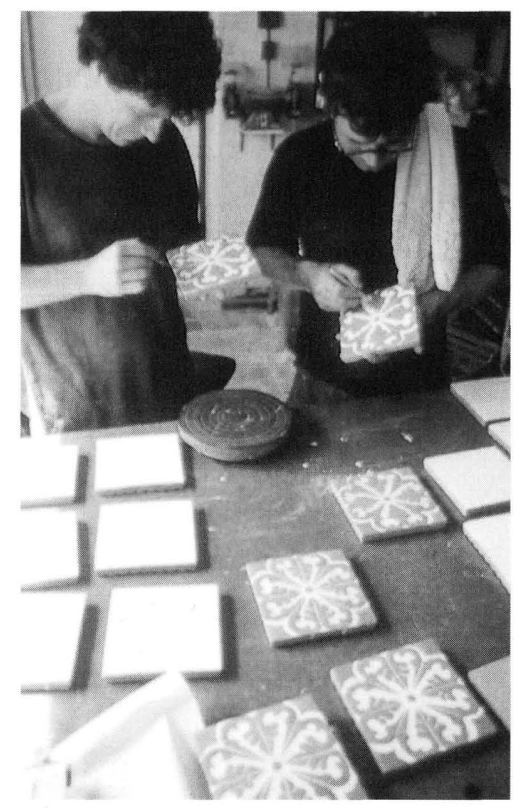

Fabricación de los azulejos del patio con técnicas antiguas. (Foto Montserrat Baldomà, junio de 1995.)

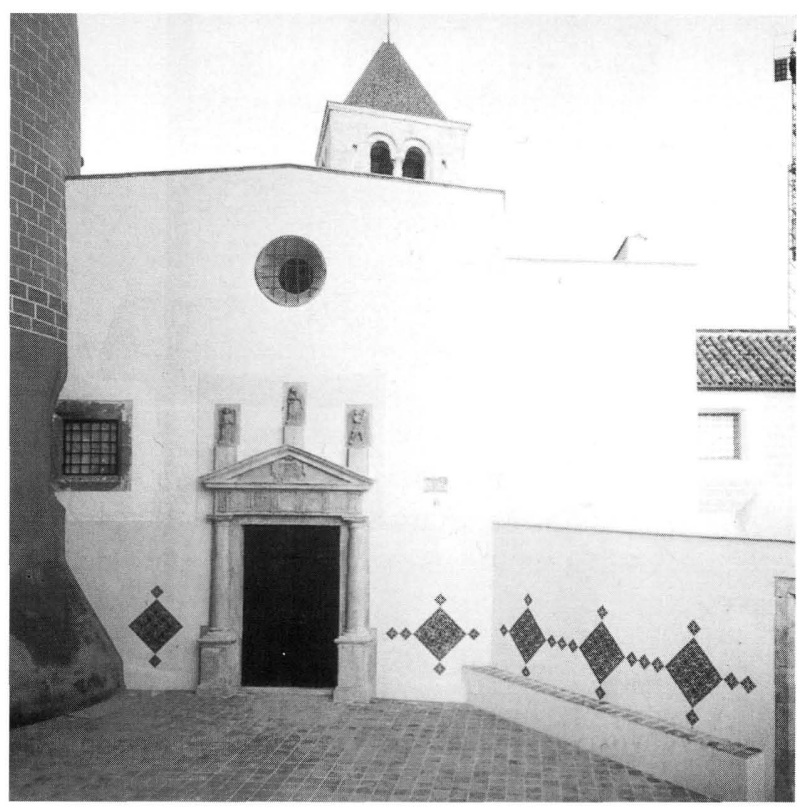

El patio de poniente, una vez restaurado. (Foto: Montserrat Baldomà, 11 demarzo de 1996.)

http://informesdelaconstruccion.revistas.csic.es 


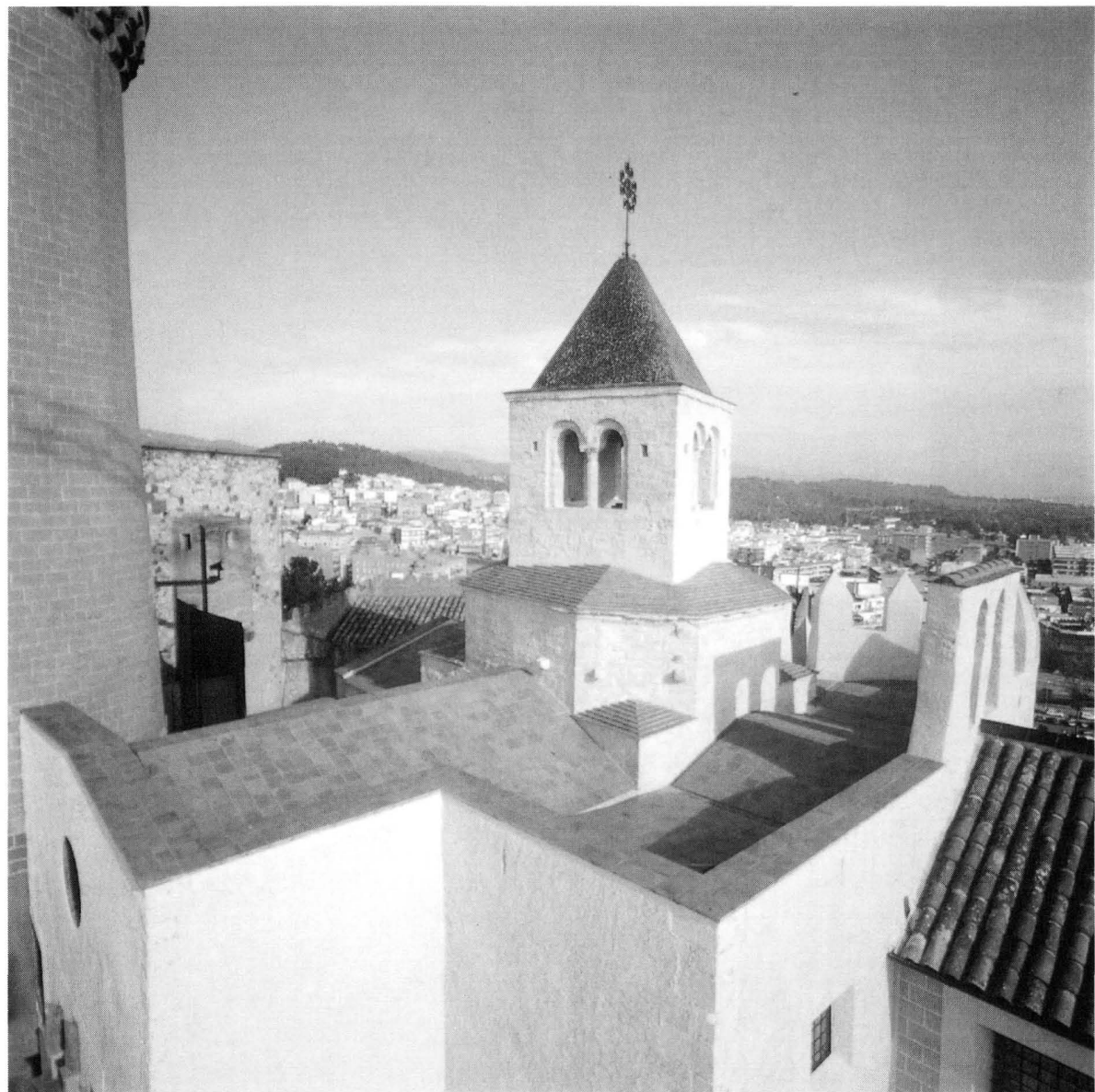

Las cubiertas y el campanario, después de la restauración. (Foto: Montserrat Baldomà, 26 de enero de 1996.$)$

La pequeña explanada que antecede a la puerta del patio se adecentó con sablón. La escalera que salva el desnivel entre ambos (que presentaba un pésimo estado) fue desmontada, numerándose todas las piezas para poder rehacerla exactamente igual, lo que se hizo una vez examinados los restos de la escalera primitiva que ocultaba.

Otra intervención exterior se hizo en el ángulo noroeste del templo. Se colocó una escalera de caracol metálica por la que se puede acceder a las cubiertas. Este acceso está restringido al personal de mantenimiento, ya que adaptar la azotea para la visita pública, con los requisitos de seguridad que hoy son exigibles, hubiera obligado a alterar todos los coronamientos (bien aumentando su altura, bien introduciendo barandas) o a disponer pasarelas extrañas a la obra primitiva. Como la contemplación cercana del campanario (o de las propias cubiertas) y, sobre todo, del lejano paisaje marítimo, es un atractivo irrenunciable, la escalera se corona con un mirador de libre acceso por los visitantes

\section{EL MONUMENTO, ELEMENTO SIGNIFICATIVO}

La potenciación dela capacidad informativa del monumento como medio para afirmar su carácter significativo,

(c) Consejo Superior de Investigaciones Científicas Licencia Creative Commons 3.0 España (by-nc) comportó en Santa María de Castelldefels, fundamentalmente, garantizar que el espectador pudiera contemplar el testimonio directo de los episodios más notables de la historia del lugar, fundamentalmente su pasado ibero y romano y el paso por la iglesia de las Brigadas Internacionales.

\section{El nuevo presbiterio}

Todos los restos de la Antigüedad descubiertos durante la excavación dela iglesia fueron consolidados y conservados, y la mayor parte, por motivos funcionales, se cubrieron con capas de grava e, incólumes, permanecen ocultos bajo el nuevo pavimento. Sin embargo, por ese interés que, especialmente para los lugareños, puede tener su contemplación, se pensó en dejar visibles una parte de esos restos. Con ese fin se diseñó la tarima de vidrio que actuará como escenario y que ocupa el lugar del antiguo presbiterio, en el ábside central. Habitualmente el interior de la tarima no es visible (ya que en la cara inferior del vidrio se adhirió una lámina de material semi-reflectante) pero gracias a una iluminación artificial oculta, los restos pueden aparecer ante el espectador.

La tarima, de $40 \mathrm{~cm}$ de altura, se realizó con piezas de vidrio laminar de $27 \mathrm{~mm}$ y lámina de butiral transparente 


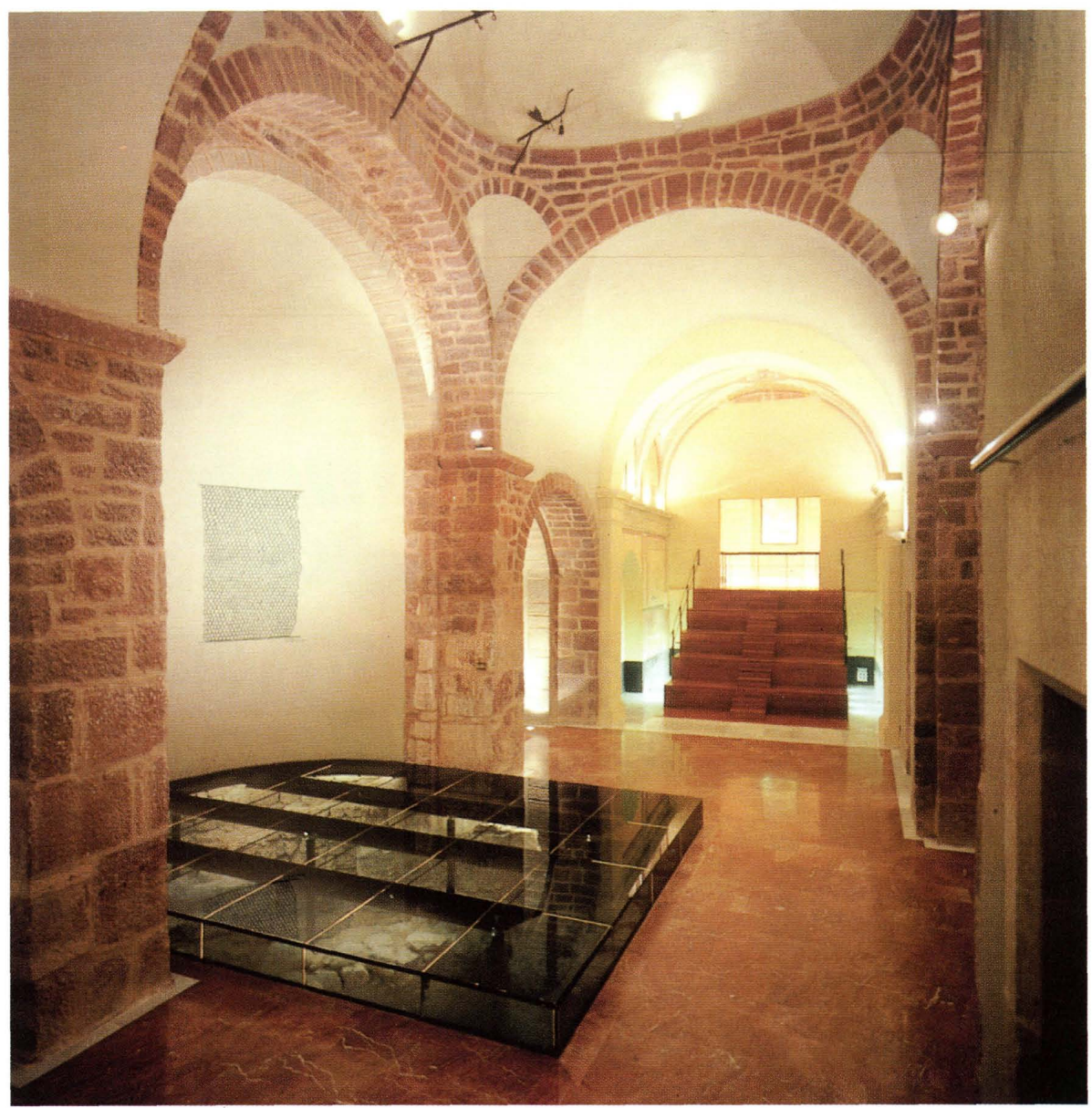

En primer término, el presbiterio iluminado para posibilitar la contemplación de los restos arqueológicos ibéricos y romanos. (Foto: Montserrat Baldomà, marzo de 1996.)

intercalada, apoyadas perimetralmente sobre otras piezas verticales del mismo tipo de vidrio y sobre una estructura metálica central de siete pilares cilíndricos, de $10 \mathrm{~cm}$ de diámetro y altura variable, apoyados sobre una base de hormigón también cilíndrica (de $20 \mathrm{~cm}$ ). Entre ambos cilindros se intercala una arandelà de acero de $14 \mathrm{~cm}$ de diámetro. Los elementos estructurales horizontales son 3 vigas IPN-160 rectas y una del mismo tipo concéntrica a la planta del ábside. El contacto de las vigas con los pilares se resuelve con unos elementos cilíndricos de acero, revestidos con acero inoxidable cromado. Entre las vigas se colocaron tirantes del mismo material que coinciden en proyección de las juntas de las placas de vidrio. En los puntos de contacto entre tirantes y vigas se sitúan anillas de acero inoxidable con una función formal. En los extremos del perfil curvado se dispusieron dos rejas metálicas de ventilación. Posteriormente, al comprobar la insuficiencia de esta aireación, se dispuso un termostato de ambiente con calefactor. Toda la estructura fue pintada con color "verde Rover", el mismo utilizado en todos los elementos metálicos aportados al edificio.

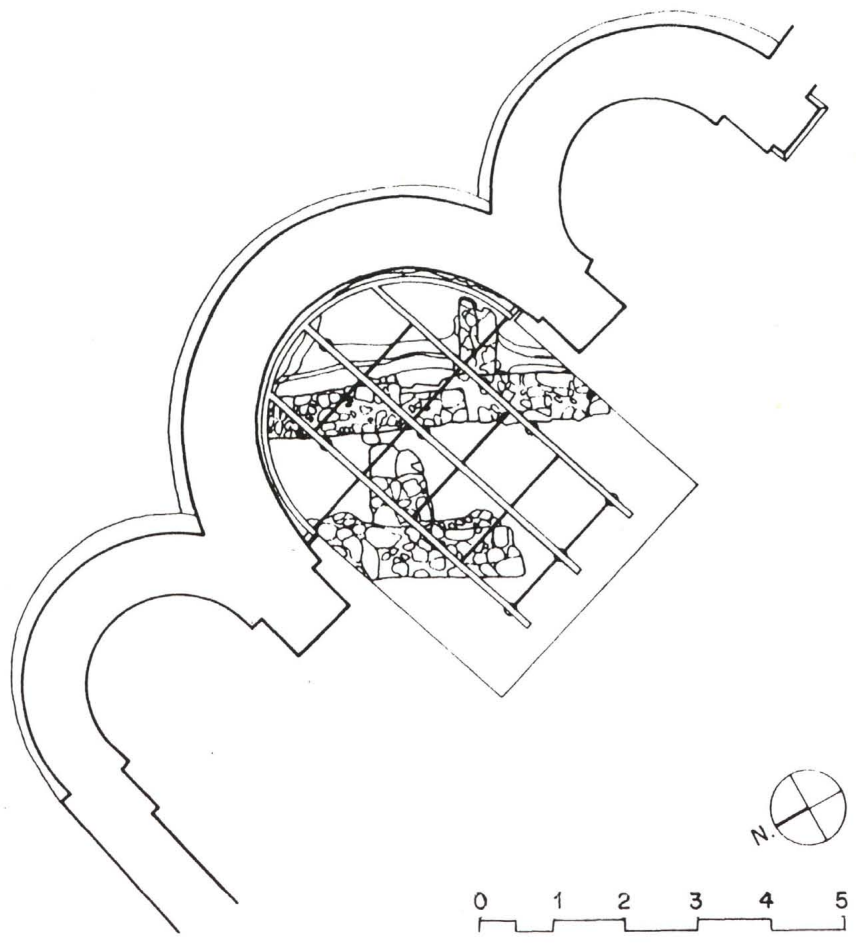

Planta de la cabecera de la iglesia, con indicación de la estructura que permite cubrir el presbiterio sin dañar los restos arqueológicos. (Dibujo: Txetxu Sanz.) 


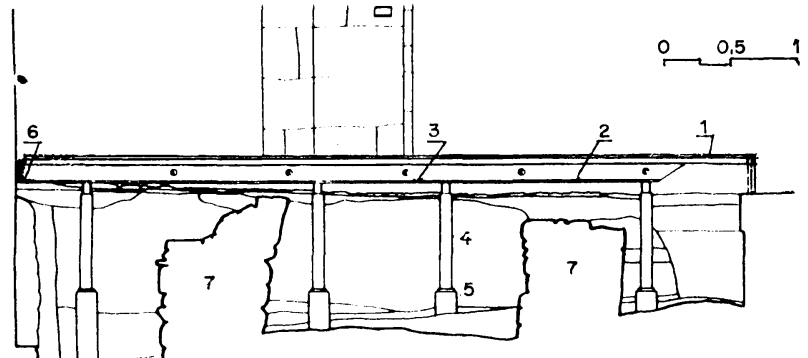

1.- Vidrio laminado. 2.-Perfil IPN-160. 3.-Tirante. 4.-Pilar metálico $\varnothing$ 100. 5.-Cimentación y platina pilar. 6.-Perfil UPN-160. 7.- Restos ibéricos y romanos.

Sección por el ábside central, con indicación de la estructura que permite cubrir el presbiterio sin dañar los restos arqueológicos. (Dibujo: Txetxu Sanz)

En el curso de los trabajos realizados en este ábside central, se descubrieron en la zona del evangelio restos de la pintura románica que debió decorarlo, realizada al temple a base de los tres colores básicos de la época: ocre, rojo y negro. La superficieconservada erarelativamente pequeña y su estado deficiente, con abundantes impactos y presencia de sales. No obstante, se adivinaban tres niveles de

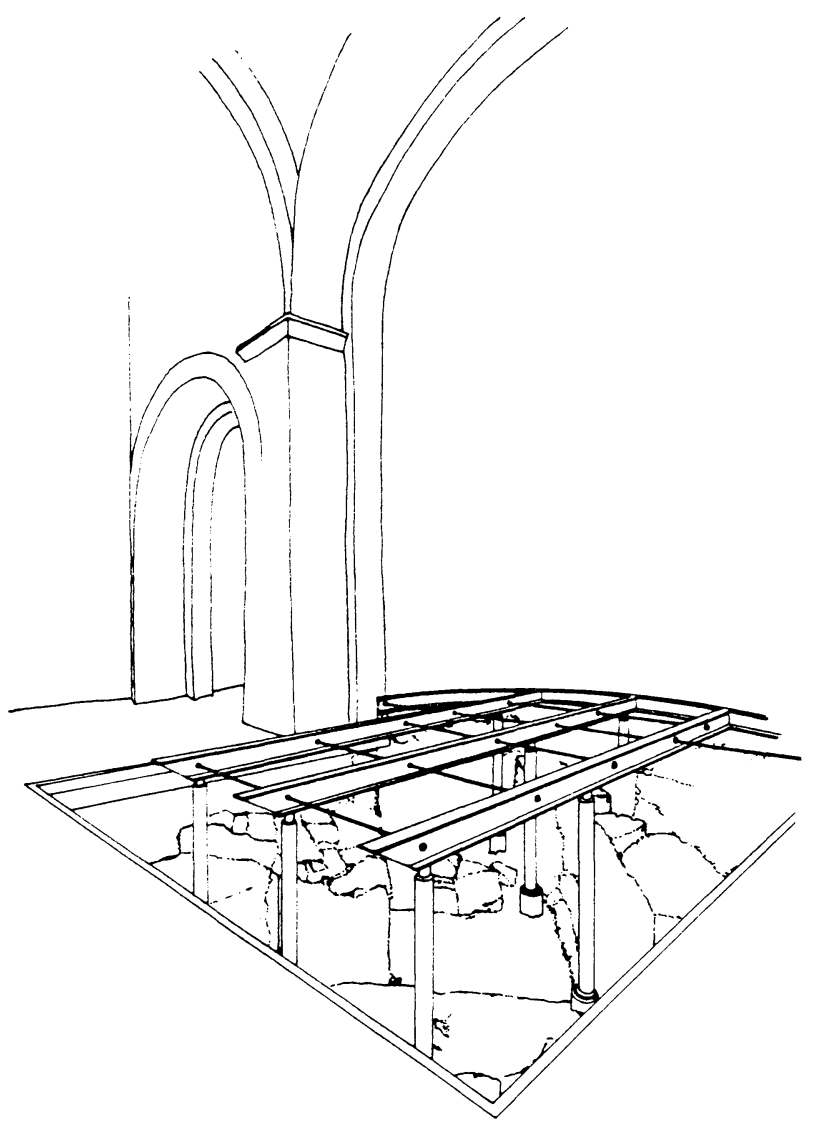

Perspectiva de la estructura del presbiterio. (Dibujo: Txetxu Sanz.) representación divididos por una decoración geométrica. Por su interés testimonial se decidió su restauración. Posteriormente, una vez revocado el resto del ábside, se decidió que en el lado de la epístola, frente a los restos restaurados de las pinturas románicas, una pintura contemporánea debía simbolizar la apropiación significativa que del monumento hace nuestra generación al restaurarlo. Fue encargado de esta misión el pintor Joan Hernández Pijuan. El 13 de diciembre de 1995, festividad de Santa Lucía, realizó con pintura acrílica el dibujo que llamó "Ornamental".

\section{La capilla de la Virgen de la Salud}

El conjunto de grafitos de 1938-1939, restaurados y conservados en la capilla dela Virgen de la Salud constituye, como se decía, otro de los puntos de interés informativo que ofrece el templo. A través de las nuevas gradas ya citadas se accede a un balcón situado en la misina cota del pavimento del antiguo camarín. Desde esta plataforma el visitante puede contemplar los 'grafitos, así como las pinturas neoclásicas de 1812 , también restauradas, entre las que se han dejado vistos dos fragmentos de las pinturas barrocas anteriores.

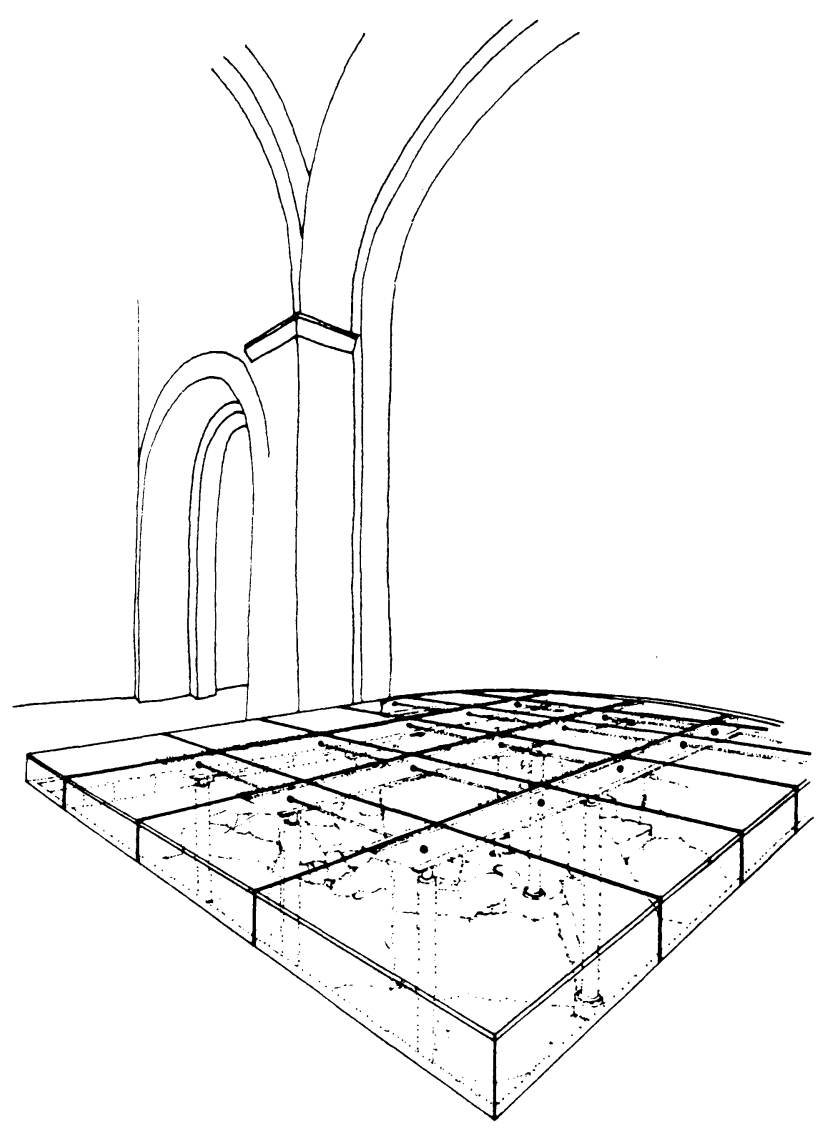

Perspectiva del nuevo presbiterio. (Dibujo: Txetxu Sanz) 


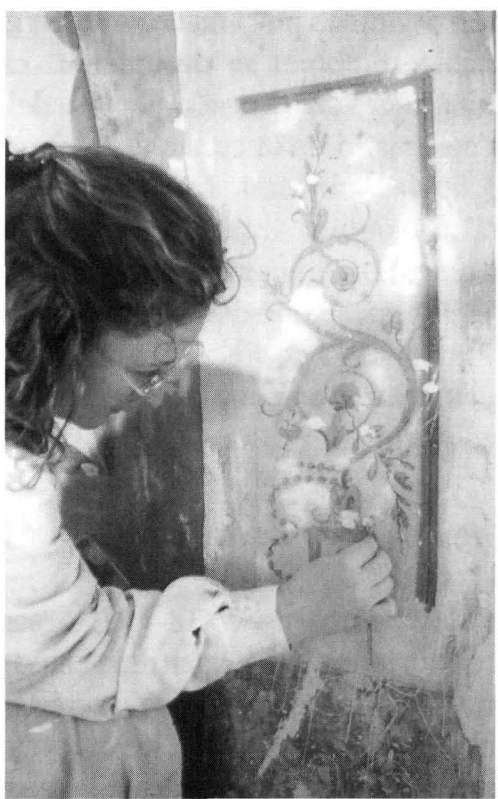

Limpieza y restauración de las pinturas y los grafitos de la capilla de la Virgen de la Salud. (Foto: Montserrat Baldomà, 9 de marzo de 1995.)

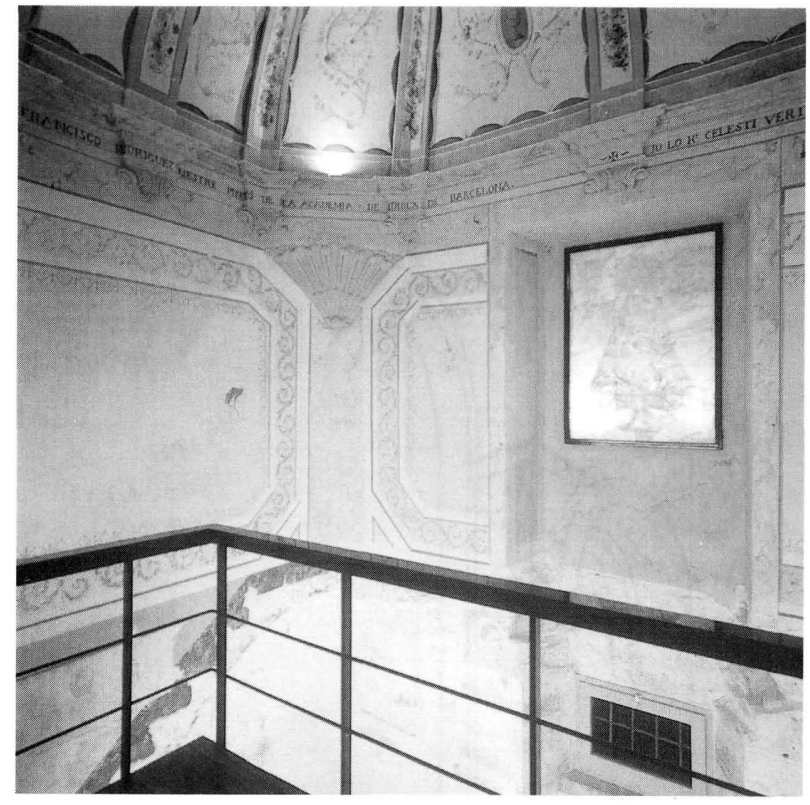

Balcón de la capilla de la Virgen de la Salud. A la derecha, la ventana con la imagen de la Virgen. (Foto: Montserrat Baldomà, 12 de marzo de 1996.)

El espacio inferior del camarín (en cuyos paramentos se pueden observar las marcas de las escaleras laterales que comunicaban con el piso superior, donde se veneraba a la Virgen, y en el que se situó, restaurada, la lápida del fundador de la capilla, mosén Andrés Cellas) es también accesible, aunque de forma más controlada, para una contemplación más cercana de los

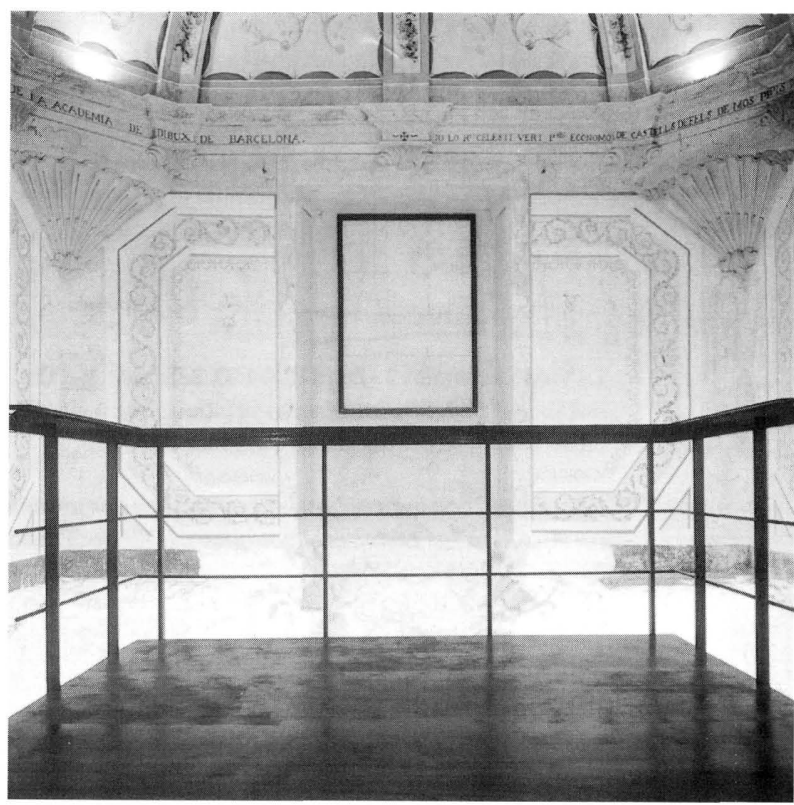

Balcón de la capilla de la Virgen de la Salud. Enfrente, la ventana. (I'oto) Montserrat Baldomà, marzo de 1996.)

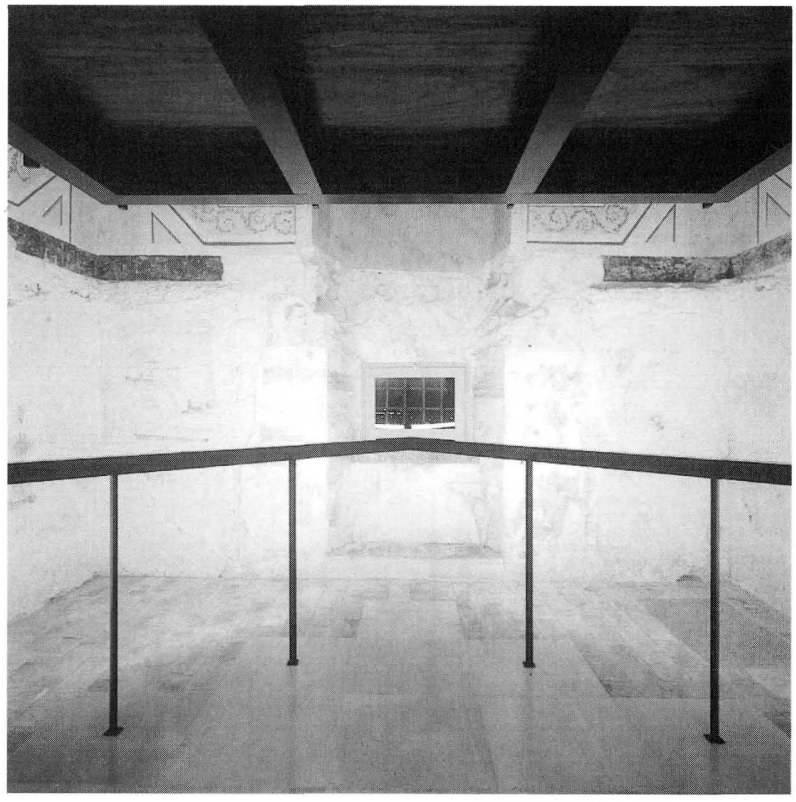

Espacio inferior de la capilla de la Virgen de la Salud, con los grafitos de la Guerra Civil, restaurados. (Foto: Montserrat Baldomà, 12 de marzo de 1996.)

grafitos, protegidos por una baranda en forma de $\mathrm{V}$ que, como la baranda del balcón superior, contiene información sobre los dibujos y acoge las lámparas lineales. Bajo el balcón, unos plafones en tres idiomas (catalán, castellano e inglés) informan al visitante sobre la Guerra Civil, las Brigadas Internacionales y su paso por Castelldefels. 


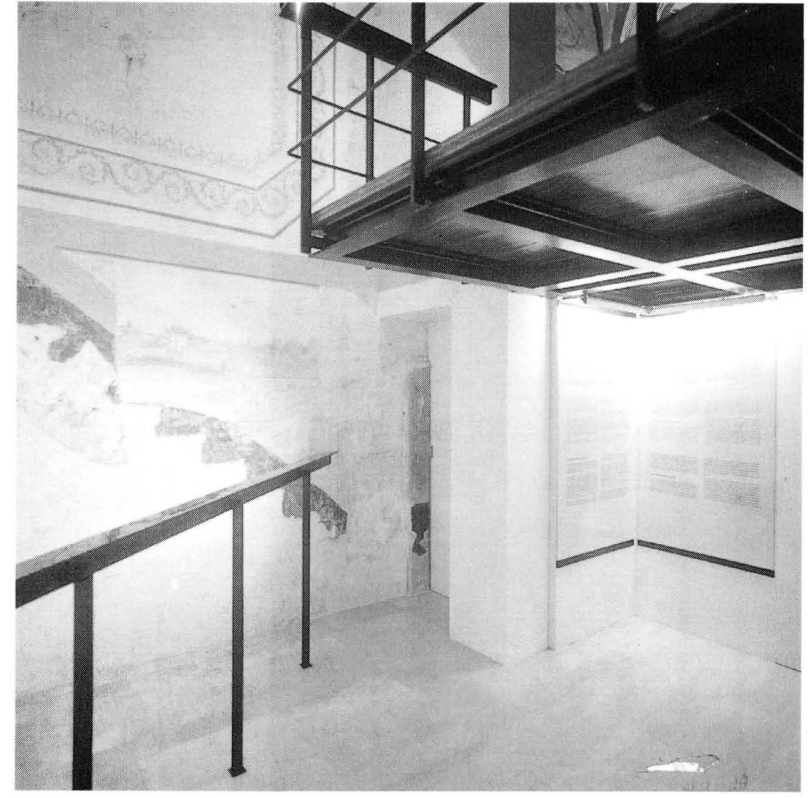

Espacio inferior de la capilla de la Virgen de la Salud, con los grafitos de la Guerra Civil y los plafones informativos. (Foto: Montserrat Baldomà, 12 de marzo de 1996.)

La ventana de la capilla situada en su eje longitudinal se ha cerrado con un mosaico de piezas de mármol rosa de Portugal, entre cuyas vetas parece adivinarse una figura. No es una ilusión óptica, sino la silueta de la patrona de la villa y titular de la capilla, venerada en aquel lugar hasta 1911, grabada en una película fotográfica situada tras el mármol. Cuando el sol se oculta al atardecer, el mármolse torna opaco y la silueta desaparece. Dos focos halógenos exteriores permiten recuperar la presencia de la imagen, si así se desea.

\section{Otros puntos de interés informativo}

La antigua capilla de San Antonio y Santa Bárbara, junto al muro norte de la nave central se habilitó para reforzar el carácter informativo del monumento. En ella se exponen algunos de los elementos más significativos encontrados durante los trabajos de restauración (dos capiteles románicos y el cippus romano), así como las maquetas de la evolución del castillo, junto a plafones informativos sobre el templo y la restauración, cuyo texto, también en tres idiomas, se esgrafió sobre vidrio de $5 \mathrm{~mm}$. El recinto se cierra hacia el exterior con lamas verticales de vidrio hueco de $26 \mathrm{~cm}$ de anchura

En la nave, junto a la puerta que permite acceder a esta capilla y a la escalera del coro, se ha situado la lápida sepulcral con escudo que antes de la Guerra Civil cerraba la tumba central del patio. Perteneció al enterramiento de Bernardo Xavier María de Garma y Pérez de Moreno, barón de Eramprunyà y propietario del castillo, fallecido

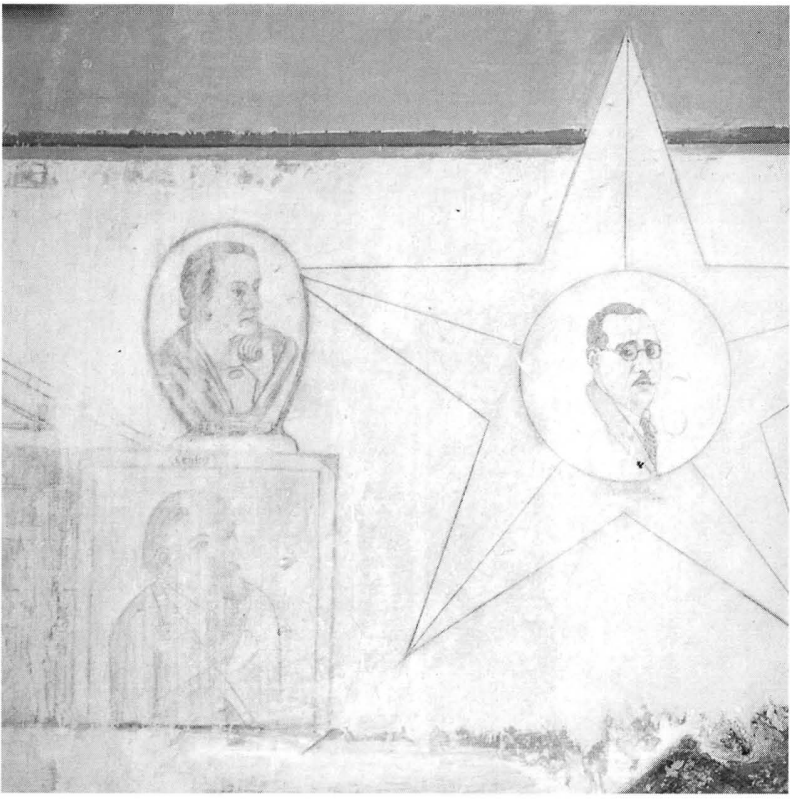

Grafitos de las Brigadas Internacionales (1938-1939), conservados en la capilla de la Virgen de la Salud. Composición en forma de retablo con diversos personajes de la época. Arriba, a la izquierda, Dolores Ibárruri, "La Pasionaria" (1895-1989). Debajo, Vladimir Myich Lenin (18701924). En la estrella de la derecha, Juan Negrin (1889-1956), primer ministro de la República Española. Dibujos: Antonio Stoffella. (Foto: Montserrat Baldomà, 12 de marzo de 1996.)

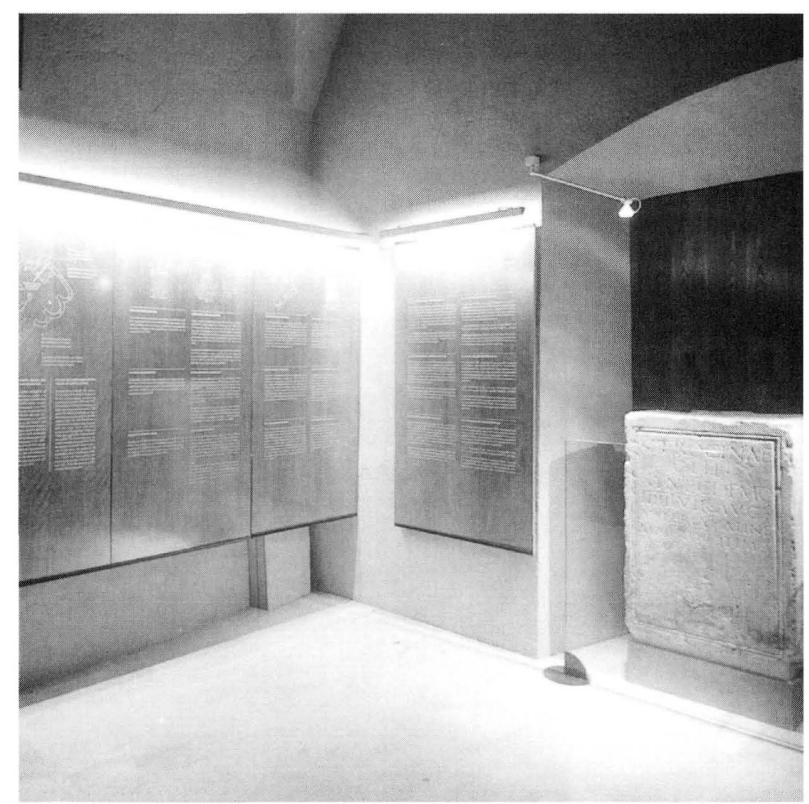

Espacio de exposición. A la derecha, el cippus romano. (Foto: Montserrat Baldomà, 7 de febrero de 1996.)

en Solsona, el 29 de marzo de 1809, hijo del ilustre heraldista Francisco Xavier de Garma y Durán. Su restauración fue laboriosa, ya que cuando fue retirada se rompió y algunos fragmentos se perdieron, debiendo ser éstos repuestos a base de morteros reintegradores. 


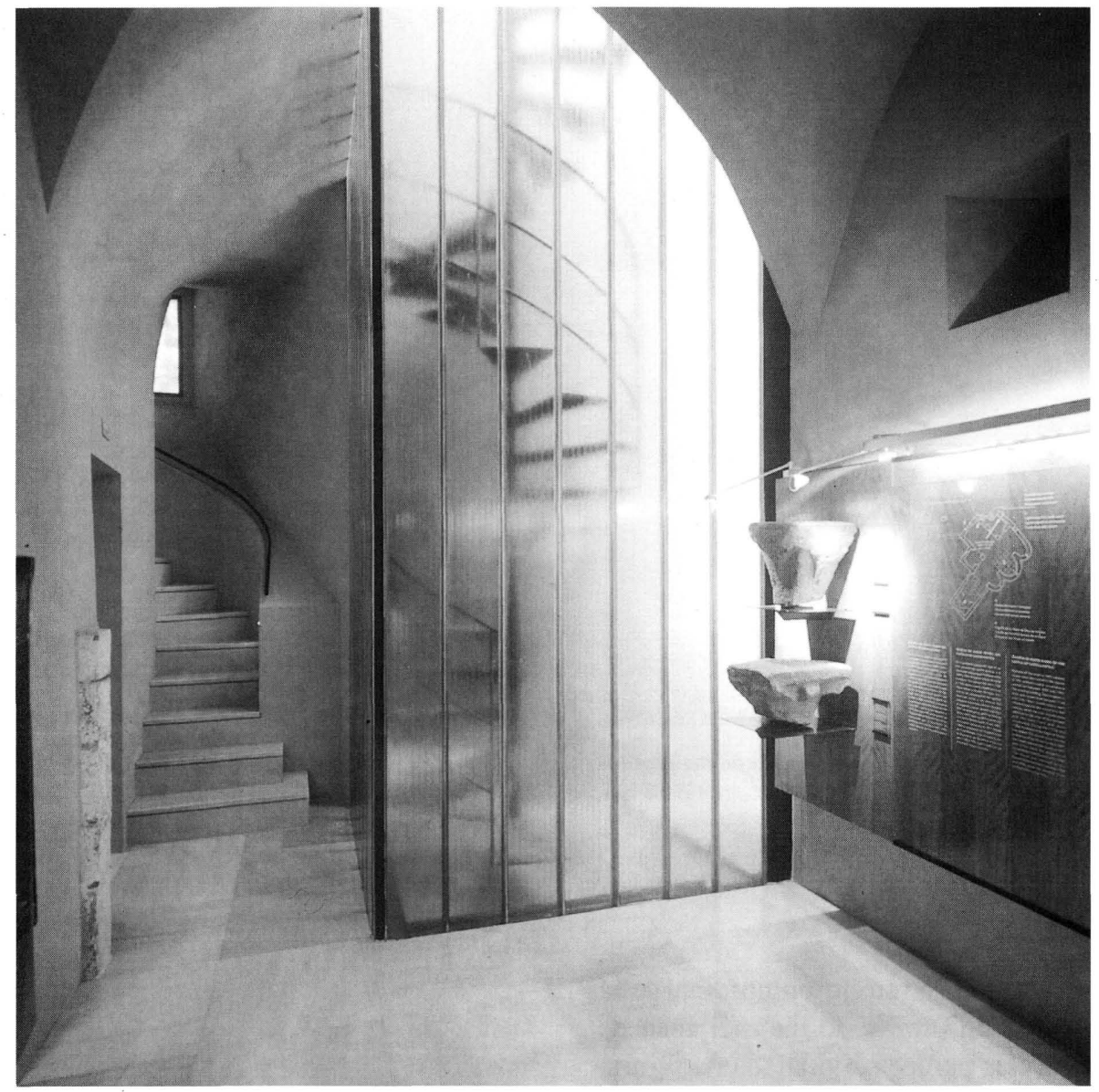

Espacio de exposición, escalera de acceso a las cubiertas (tras el vidrio) yescalera de acceso al coro. (Foto: Montserrat Baldomà, 12 de marzo de 1996.)

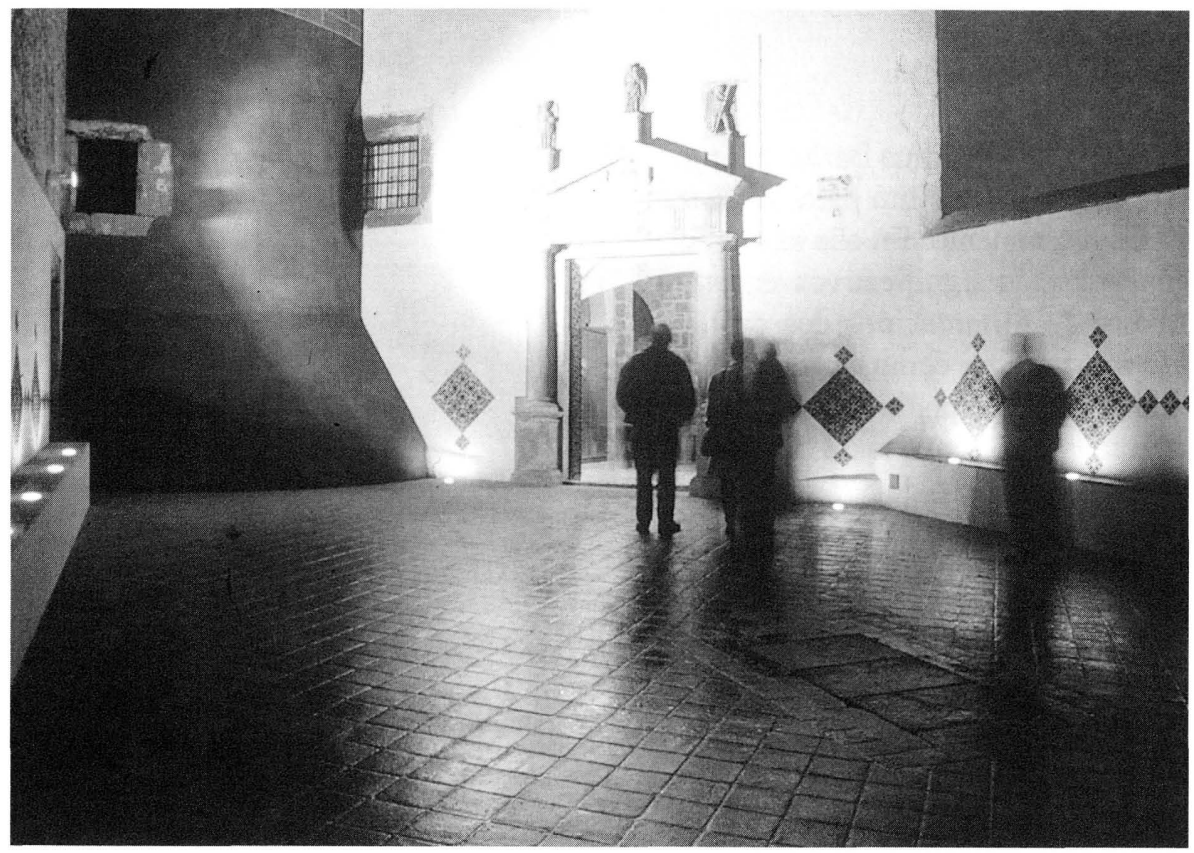

Iluminación nocturna del patio de poniente. (Foto: Montserrat Baldomà, 15 de diciembre de 1995.) (c) Consejo Superior de Investigaciones Científicas Licencia Creative Commons 3.0 España (by-nc) 
En la antigua capilla del Rosario -que se utiliza también como espacio auxiliar de las actividades culturales que se celebran en la iglesia y que, como su simétrica, no conservaba ningún rastro de su decoración y mobiliario primitivos-, y tamibién bajo las gradas de la capilla de la Virgen de la Salud, se guardan, también restaurados, otros elementos desmontados o descubiertos en el curso de las obras (lápidas, jambas y dinteles, etc.) que deben ser conservados para posibles estudios posteriores, pero tienen menor interés para los visitantes, por lo que el acceso a estos lugares es restringido. También está reservado a especialistas la visita a los restos conservados bajo el presbiterio, a los que se accede por una trampa situada en el ámbito del ábside de mediodía, protegida por una placa de madera inclinada (para permitir la aireación) en la que consta el año en que se acabó la restauración: 1995.
(1) Los trabajos técnicos y científicos realizados con motivo de la restauración de Santa María del castillo de Castelldefels se refieren a los aspectos siguientes (no se incluyen los dictámenes previos y las memorias relativas a la excavación arqueológica y a los trabajos derestauración pictórica y escultórica):

Análisis histórico-arqueológico:

- Estudio de restos humanos (antropología física).

- Estudio ceramológico.

- Clasificación y estudio de monedas.

- Estudio de fauna.

Análisis histórico-documental:

- Estudio de las fuentes documentales (siglos XII al XX).

- Estudio sobre los diversos caminos de acceso a la iglesia, la rectoría y el castillo a lo largo de la historia.

- Estudio sobre la presencia de brigadistas internacionales en el castillo(1938-1939).

Análisis histórico-artístico:
- Estudio de la pintura mural románica.

- Estudio de la portada renacentista.

- Inventario y análisis artístico de elementos depiedra hallados en las excavaciones y durante las obras.

- Inventario y análisis de los grabados y grafitos de la sacristía antes de proceder a su arrancadura.

- Inventario y análisis artístico de los grafitos de la capilla de la Salud.

Análisis histórico-constructivo:

- Aproximación a la evolución constructiva del edificio a través del estudio de los materiales.

Análisis fisico-constructivo:

- Datos geográficos y ambientales del lugar.

- Informe técnico sobre los revestimientos interiores y exteriores.

Análisis arquitectónico:

- Estudio métrico y compositivo de la iglesia.

\section{Ficha técnica}

Promotor: Ayuntamiento de Castelldefels.

Realización: Diputación de Barcelona, Servicio de Patrimonio Arquitectónico Local (SPAL). 1989-1995.

Dirección general: Antoni González Moreno-Navarro.

Investigación histórica: Arqueología: Alberto López Mullor, Alvar Caixal, Imma Estany, Xavier Fierro, Montserrat Gumà, Valentín Niño, Helena Kirchner y Xavier Solé; antropología física: Domènec Campillo, Oriol Mercadal y Anna Mestre y ; numismática: María Clua; paleobiología: Lluís Rius. Historia documental: Anna Castellano y Manuel González (brigadistas internacionales); historia del arte: María Antònia Carrasco, Raquel Lacuesta, Núria Pinos, Jaume Sandoval, Maria José Sureda; historia de la construcción: Josep Maria Moreno; estudio métrico: Rafael Vila.

Intervención arquitectónica: Arquitecto: Antoni González Moreno-Navarro. Arquitectos colaboradores: Anna Albó, M. Àngels Bardolet, Pau Carbó y Joan Casadevall (revestimientos). Arquitecto técnico: Jaume Bassas. Constructor: URCOTEX, I. SA (Josep Mª Sala, arquitecto; Albert Martí, arquitecto técnico; Manuel Márquez, Esteve Malagarriga, Ramón Fíguls, encargados).

Trabajos especiales: Restauración pintura mural y grafitos: Clara Payàs, Núria Ros, Marta Díaz, Eulàlia Martínez, Margarita Nicolau, Eva Corsellas (ARCOR, Barcelona). Restauración de piedra: Pilar Díaz, M. Soledad Dueñas, Montserrat Farrán, Antoni Ciuraneta (AIGUABLAVA, Barcelona). Museización: Lourdes Borrell, Olga de la Cruz(BBCR, Barcelona). Diseñográfico: Quim Boix (BBCR, Barcelona). Reproducción deazulejos: Manuel Diestre, Joaquim Toribio, Jordi Salvador (Tallers El Sot, Barcelona). 